Article

\title{
Finite Element Analysis of the State of Stresses on the Structures of Buildings Influenced by Underground Mining of Hard Coal Seams in the Jiu Valley Basin (Romania)
}

\author{
Dacian Paul Marian ${ }^{1}$, Ilie Onica ${ }^{1}{ }^{*}$, Ramona-Rafila Marian ${ }^{1}$ and Dacian-Andrei Floarea ${ }^{2}$ \\ 1 The Department of Mining Engineering, Mining Surveying and Constructions, University of Petroşani, \\ 332006 Petroşani, Romania; dacian_top@yahoo.com (D.P.M.); ramona_nicolae4@yahoo.com (R.-R.M.) \\ 2 Hunedoara Energy Holding, 332015 Petroşani, Romania; dacian.floarea@gmail.com \\ * Correspondence: ilieonica@upet.ro; Tel.: +40-0729-066-723
}

Received: 20 January 2020; Accepted: 16 February 2020; Published: 20 February 2020

\begin{abstract}
The hard coal seams in the Jiu Valley mining basin have been mined with different mining methods and technologies, including with the complete caving of the surrounding rocks and with top coal caving. These mining systems have led to the degradation of the ground surface by producing subsidence of the land, ranging from a few meters up to tens of meters, in the areas with thick coal seams with high dips. When the limits of the main safety pillars are accidentally exceeded whilst mining, buildings situated either below the ground or on the surface are affected. In the future, the possibility exists of mining some of the very large reserves that are immobilized in the main safety pillars, where the gentle dip seams are stored. In consideration of the above, in order to study the behaviour of typical buildings that are under the influence of underground mining and to develop a model of the stress state in the structural elements of the structures, finite element modelling is used. As such, several modelled buildings with one, two, and three levels were generated, as well as buildings with two levels and with different lengths. These buildings were built of reinforced concrete panels or brick masonry and were subjected to the mining influence of a panel specific to the mines in the Jiu Valley basin, sequentially extracted with a longwall coal face method at different operating heights, with the use of roof control by caving of rocks and with top coal caving methods. Following the analysis of the major principal (tensile) stresses and minor principal (compressive) stresses, a series of conclusions regarding the behaviour of these buildings that are under the influence of the underground mining is revealed. In this context, it was concluded that the value and location of the stresses developed in the structure of the buildings depend mainly on the extension of the panel and the volume of the goaf, the relative position of the building in respect to the coal face line, and the length of the building.
\end{abstract}

Keywords: coal underground mining; caving roof control; top coal caving; subsidence; displacement; stress; strain; building; numerical modelling; finite element method

\section{Introduction}

The coal basin of the Jiu Valley (Figure 1) is geographically located in the center of the country and contains the most important hard coal deposit in Romania, both in terms of balance reserves exceeding one billion tons and in relation to the special coking characteristics of the western coal seams in the basin. This deposit has been known and mined sporadically since the 19th century, but its systematic mining only began after World War II, reaching a maximum output capacity of over $8-10$ million tons per year after 1980. The hard coal deposit covers an area of $163 \mathrm{~km}^{2}$ and has been 
delimited in 17 mining fields, within which 13 mines have been exploited. Following several stages of reorganization and the closure of some mining perimeters starting in the 1990s, only 4 mines currently remain active, resulting a corresponding reduction of production capacities [1].

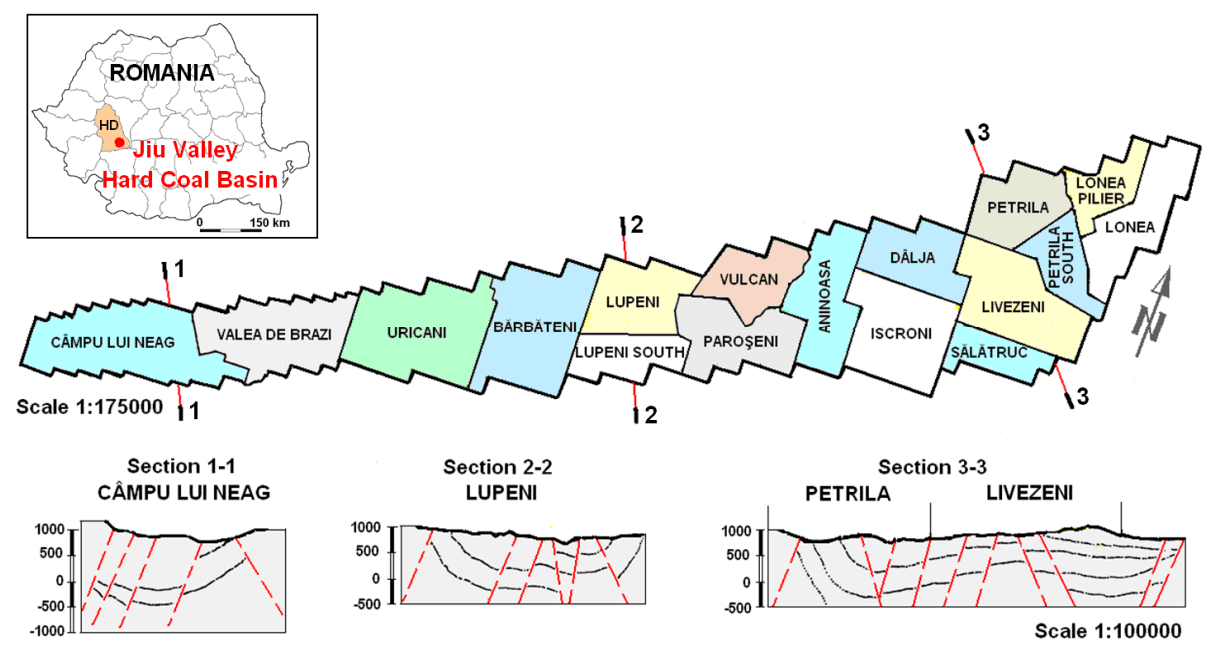

Figure 1. Map of the division of the Jiu Valley coal basin into mining fields.

From a geological point of view, the Jiu Valley coal basin is an epistructural depression consisting of a crystalline foundation and Molasic cover sedimentary deposits, attributed to the Upper Cretaceous (Maestrichtian), Paleogene, and Miocene periods, largely covered by possible Quaternary formations. The sedimentary deposits comprise the following main units: the Getic domain, the autochthonous domain, and the sedimentary complex of the basin with the Chattian level, which also includes coal seams.

The coal reserves are intensely tectonized, with a significant variation in the qualitative and quantitative parameters, generating geological blocks with small extensions, most of which range between 200 and $300 \mathrm{~m}$ (Figure 2).

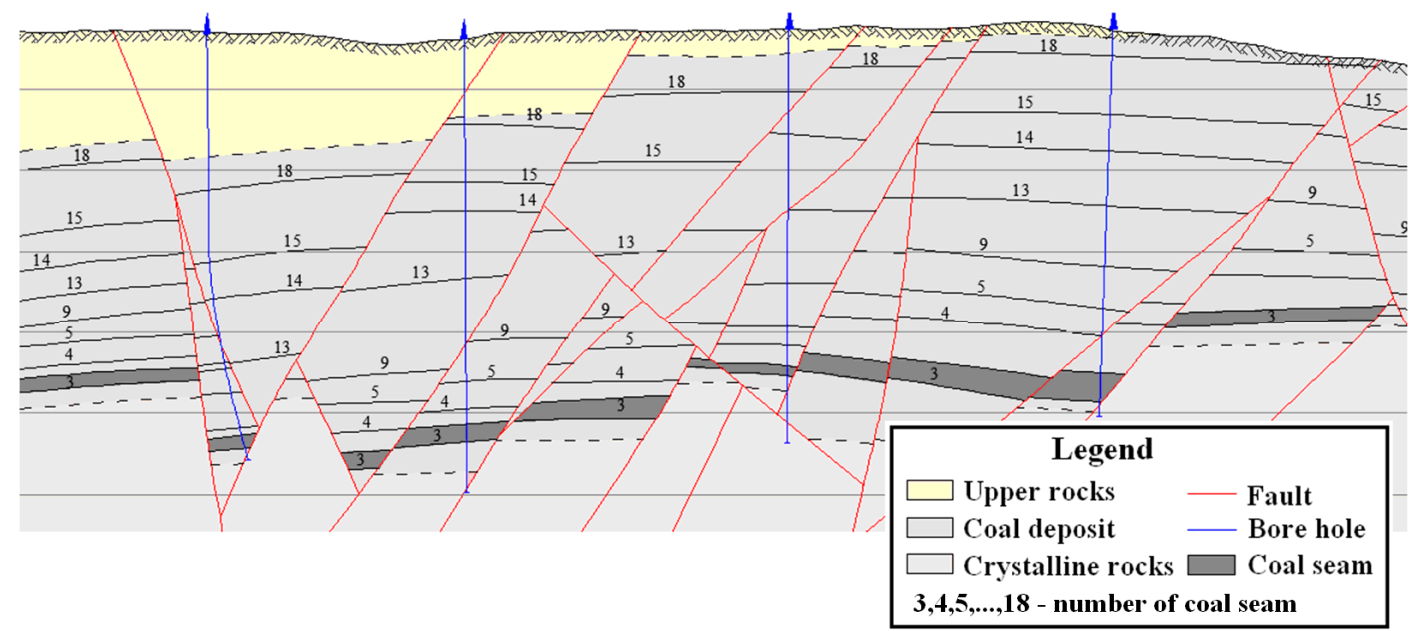

Figure 2. Representative vertical cross-section of the Jiu Valley coal basin in the Paroşeni mining perimeter.

Within this basin, 22 coal seams have been identified, of which the highest weight is held by coal seam number 3 at $48 \%$, followed by coal seam number 5 at $12 \%$. Coal seam number 3 is located at a distance of 25-30 m from the Rupellian-Chatian limits. This coal seam has variable thicknesses ranging from $0.5 \mathrm{~m}$ to $34 \mathrm{~m}$, sometimes even over $50 \mathrm{~m}$, with large differences depending on the direction and dip of the seam. The largest thickness is found in the mining fields on the eastern side of the basin. 
The dips of the coal seams are very diverse, starting with the high dips towards the border of the basin, turning into gentle dips and then horizontal dips towards the center.

Because the genesis of the coal deposit is sedimentary, the most common rocks in this basin are limestone, marls, clays, clayish or marlish sandstones, and conglomerates, the compressive strengths of which are between 15 and $16 \mathrm{MPa}$, and sometimes even over 50-60 MPa. Generally, these rocks have a relatively low stability and are prone to collapsing.

Over time, as a result of the mining of thick coal seams in the Jiu Valley coal basin, deformations have appeared on the ground surface, which in some cases have even led to the destruction of buildings located on the surface and of some main underground mining works. In this respect, the effects mining activities have on the surroundings receive significant global attention due to the nature of their environmental and social responsibilities [2]. In addition to the destruction of land and buildings, these phenomena have important impacts on the environment, including the impossibility of reusing the land for buildings or for agriculture; disturbance of groundwater flow regimes and hydrostatic levels, and in rarer cases pollution of the same area; and emissions into the atmosphere through fissures and cracks of methane (greenhouse) gas and of gases resulting from the spontaneous combustion of coal. Furthermore, the destruction of some buildings [3] owned by disadvantaged families, together with other economic factors, have resulted in the emergence of significant social phenomena $[4,5]$.

An important reserve of coal measuring almost one billion tons (equal to the balance coal reserve) is also immobilized in the main safety pillars of the buildings, roads, railways, and watercourses that cross the basin from east to west, and in the pillars of some main underground mining works (shafts, galleries, inclined planes, etc.). Failure to observe the limits of the main safety pillars has led to some of these objects being affected on the surface or underground.

The greatest damage to the ground surface has been caused by the mining of coal seams in horizontal slices, leading to total collapse of the surrounding rocks of the thick, large dip seams located at the limits of the coal basin, where the presence of construction is insignificant. As such, the purpose of the investigations reviewed in this article is to clarify the behaviour of the buildings located towards the center of the basin, which are affected by the underground mining of the thick coal seams with low dips, in the event of future extraction of the coal reserves from the main safety pillars or following an instance where the limits of these pillars are accidentally exceeded. The geo-mining conditions introduced in the numerical models are extreme ones that can occur only in the case of practicing roof control by caving of integral rocks [6], and less so in conditions of total stowing (filling) of the gob [7-9] (which will apply only in the event of a future decision to exploit the main safety pillars). The post-mining area can be filled with a hydraulic, dry, or paste filling. The choice of the backfilling method depends, among other things, on the time of backfilling, equipment, costs, and above all, the limitation of the impact of mining on the surface $[10,11]$.

It is preferred to model the coal mining based on the total caving of roof rocks in order to achieve both the accidental damage of buildings through exceeding the pillar limits, as well as the planned mining of the coal reserves in the main safety pillars.

In general, underground mining operations lead to significant disturbances in the balance of the roof rocks, and sometimes in the floor of the mined coal seam. Finally, under certain conditions, this movement is transmitted to the surface, causing damage to both the ground surface and the objects located in the area of influence of the coal seam mining area [12,13]. The magnitude of these deformations depends on the following parameters: number of seams worked on; their thickness; the dimensions of the fields worked on within each seam; the exploitation method; liquidation of the space worked on; geological and hydrogeological overburden structures; and tectonics, strength, and strain properties of the rock mass and rock strata [14].

Depending on the character of the ground deformation, the following factors differ: (a) continuous or trough subsidence, involving the formation of a smooth surface subsidence profile that is free of step changes; (b) a discontinuous subsidence, which is characterized by large surface displacements over limited surface areas and the formation of steps or discontinuities in the surface profile [15]. 
In the case of continuous subsidence, the trough is characterized by terrain deformation indicators, such as: subsidence $w$, horizontal displacement $u$, horizontal strain $\varepsilon$ and vertical strain $\varepsilon(z)$, slope $T$, and radius of curvature $R$ [14].

The main parameters of the subsidence troughs are determined separately for each mining basin, and even for each mining field, with the help of topographic measurements of high accuracy. Across the globe, the monitoring of deformation over time of the surface lands under the influence of underground mining, especially in the areas of special interest, is carried out systematically with the help of topographic and photogrammetric methods, global positioning systems (GPS) technology, interferometric synthetic aperture radar (InSAR) [16] together geographic information systems (GIS) [17], and by laser scanning (either land or aerial) [18].

The prognosis and the study of the deformations of the lands affected by the underground mining can be done with the aid of empirical methods (profile functions and influence functions); physical models (based on rock like or optically active materials); analytical models (plate and beam theory [7], etc.)); and numerical models (finite element, finite difference, boundary element, and distinct element methods [19-21]).

The land deformation also affects the surface buildings and underground mining construction within the radius of the coal mining influence.

While in the specialized literature there are numerous in-depth studies on the numerical modelling of the influence of tunnel excavation on surface buildings [22-32], in the case of underground mining of deposits of useful mineral substances, these studies are less frequent [3,33-35]. Therefore, we consider that this study has a certain contribution to the elucidation of the behaviour of buildings under the influence of coal seam mining by means of the longwall faces, especially by analyzing the development of the state of stresses in the structural elements of the buildings.

Over time, the assessment of the damage to the surface structures caused by the underground mining has become the concern of many experts.

It is quite difficult to quantitatively determine the destruction of the surface structures due to underground mining. The deformations induced in different structures, once they exceed the critical values of the characteristics of the structural elements, cause damage. The amount and intensity of the damage depends on their ability to take over the additional stresses generated by the deformations transmitted by the ground. Therefore, the maximum permissible deformations of the ground and structures vary from country to country, and even frequently from one region to another region in the same country [36].

Specialists from certain countries (UK, China, Russia, USA, Australia, and others) affected by the phenomenon of mining subsidence have developed methods of assessing the damage of buildings located in the mining subsidence areas. Most of these methods are empirical, based on observations made on degraded buildings. There are also various methods based on simple mechanical and analytical calculations [37]. In the same context, to study the impact of mining subsidence on masonry buildings, Abdallah and Verdel used a numerical experimental design, represented by distinct element models of a masonry wall, where masonry blocks are explicitly taken into account, along with statistical analysis and surface responses according to the positions of buildings in the convex or the concave curvature zones of a subsidence trough [3].

The vulnerability analysis of a structure in relation to ground deformation is difficult to perform due to the quantity of the necessary repair works, uncertainty regarding requests, and the uncertainty of the different methods used to assess the damage. The vulnerability functions define the damage according to the intensity of the danger and are expressed either by empirical methods or analytical methods [38]. As such, this problem has elicited concern for many researchers.

The tensile and compressive strains are clearly the main factors that cause the destruction of all types of structures on the surface. The degree of transmission of horizontal strain depends on the rigidity of a structure relative to that of the ground [38,39]. Structures are sensitive to all types of 
terrain deformation, except for pure subsidence and pure displacement, while transport structures are sensitive to pure subsidence [39].

Bruhn et al. [40] proposed a classification scheme founded on the basic characteristics of the damage, quantified according to a severity index that takes into account both the damage to walls and floors and their rehabilitation costs. Additionally, Sengupta [41] proposes a method of classification in which the characteristics of buildings are divided into different categories in accordance with their response to ground surface deformation. The final category represents the sum of all categories of the diverse characteristics of buildings, which includes building foundations, superstructure materials, the ratio between the length of a building and the radius of influence, and the ratio between the height of a building and its length.

The correlation between the values of the deformations and the damage caused to the buildings is established by Wardell [42] in five classes, in which the severity of the damage caused to the buildings is assessed according to their length and the deformation to the foundations. Later, other experts detailed this classification into six classes for two-storey brick structures, taking into consideration deflection ratios, extensions, and crack width $[21,43,44]$.

Taking into account the factors presented above, the finite element analysis of the behavior of buildings under the influence of the underground mining of thick coal seams from the Jiu Valley, and the studies synthesized in this article, our work has the following practical motivations:

- $\quad$ investigating the potential mining of a lost reserve in the main safety pillars of cities of over 1 billion tons;

- $\quad$ investigating accidental mining of the safety pillars of the buildings.

We note that the finite element analysis of the building stability under the influence of coal seam mining in the Jiu Valley is performed for the first time under the conditions of the most important coal basin in Romania. In addition, there is a drastic lack of such numerical analyses in the literature, due to existence of very large underground mining excavations of the order of hundreds of thousands of $\mathrm{m}^{3}$ (which, in this case, led to the generation of numerical models with a volume of over 500 million $\mathrm{m}^{3}$ ) compared to the small sizes of the buildings. These constraints have created special problems, both in terms of model construction and calculations. Therefore, the closest numerical models known in the literature are those relating to buildings under the influence of tunnels (excavations with a small volume of the order of thousands of $\mathrm{m}^{3}$ ), which involve models with much smaller dimensions (with a volume of the order of hundreds of thousands of $\mathrm{m}^{3}$ ) and implicitly require less important computing resources [20-30]. Therefore, this numerical modelling analysis, which is specific to civil engineering, has allowed consideration of many details regarding the construction of models and constitutive laws applied to rocks and materials, which are much more complex than in the case of mining engineering problems (as they are treated in this article).

\section{Examples of Deformation of the Ground Surface as a Result of the Underground Mining of the Jiu Valley Coal Seams}

\subsection{The Case of the Livezeni Colliery}

A significant example of ground surface deformation is the route marked along the road that accesses the tourist areas of the Parâng Mountains, which is under the influence of the mining of panels P (3-4), P3-TCC, P5, P5A-TCC, and P6 in coal seam 3, block VI A, Livezeni colliery. Monitoring is done through a station consisting of 50 landmarks, stretched over a length of $1489 \mathrm{~m}$ (Figure 3). The topographic observations have been executed every 3 months, starting in 2001.

Thick coal seam number 3, related to panels P (3-4), P5, and P6, was exploited in inclined slices, with a thickness of about $2.5 \mathrm{~m}$, with complex mechanized longwall faces and roof control by the caving of rocks; the P3-TCC and P5A-TCC panels were extracted by top coal caving [6]. The average height of overburden rocks in the mined panels is $336 \mathrm{~m}$. The dimensions of the excavations resulting from coal extraction in the five panels are summarized in Table 1. 


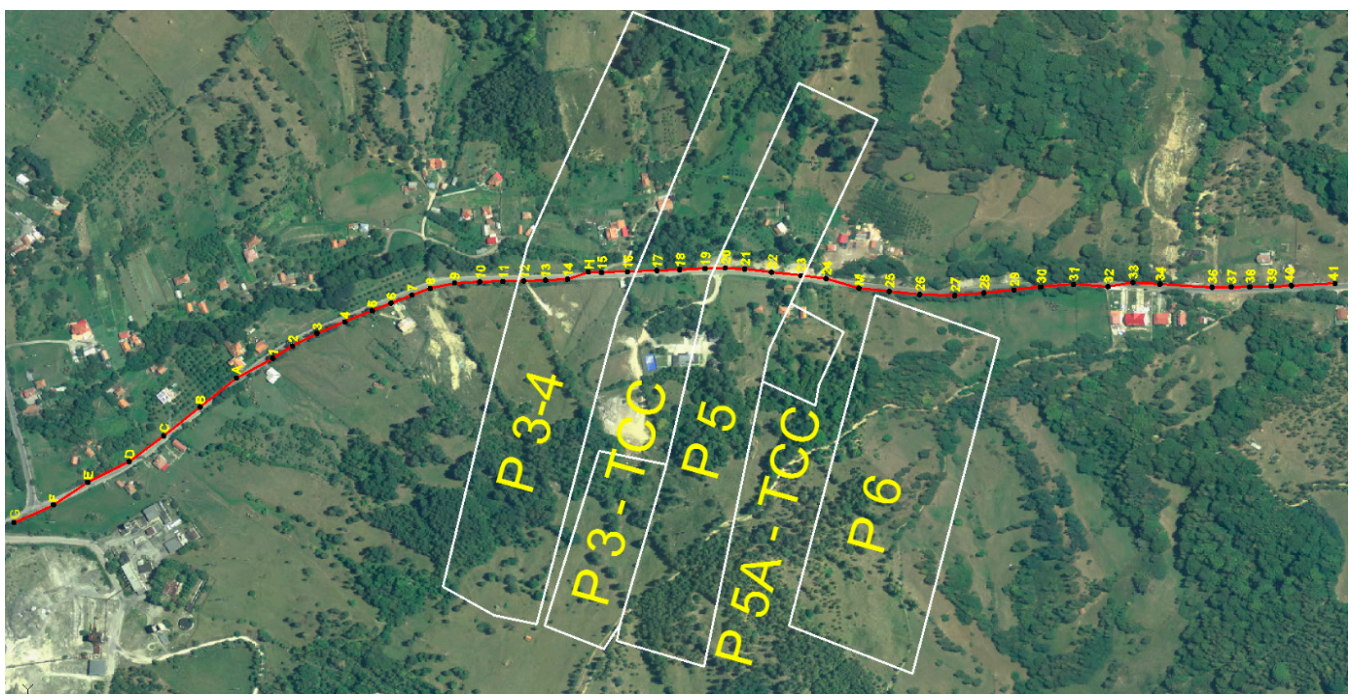

Figure 3. Plane view of the land surface, with the monitoring route and the panels used.

Table 1. Geometric characteristics of the panels on coal seam number 3, block VI A, Livezeni.

\begin{tabular}{ccccc}
\hline Panel & Mining Period & Mining Thickness, $(\mathbf{m})$ & Coal Face Length, $(\mathbf{m})$ & Panel Length, $(\mathbf{m})$ \\
\hline P (3-4) & $12.1986-01.2003$ & 10 & 110 & 656 \\
P3-TCC & $06.2003-10.2006$ & 10 & 73 & 202 \\
P5 & $06.1993-09.2002$ & 12.5 & 92 & 620 \\
P5A-TCC & $11.2009-10.2010$ & 10 & 64 & 86 \\
P6 & $06.2004-11.2006$ & 2.5 & 139 & 368 \\
\hline
\end{tabular}

Starting from the measured values, until 2008, the main parameters of the subsidence trough were determined (subsidence, horizontal displacement, horizontal specific strain, and tilt), after which only subsidence was determined [45].

The subsidence trough that appeared on the ground surface is a composite trough, resulting from the overlapping effects of the mining of the four panels presented in Table 1. It has an irregular shape due to the composition of the four individual subsidence troughs, but also due to the fact that the tracking alignment is located at the edge of the mined panels, where the transverse deviations are maximal. The development of these parameters in time is graphically represented in Figures 4 and 5 . The maximum subsidence measured in November 2016 was about $1000 \mathrm{~mm}$. Starting with the 21st month from the beginning of the observations, there has been a reduction in the deformation rate from around $20 \mathrm{~mm} / \mathrm{month}$ to around $8 \mathrm{~mm} / \mathrm{month}$ (i.e., entry into the secondary phase of evolution of the subsidence trough since 2003), and starting with the 60th month there has been an even greater reduction of the deformation rate to approximately $2 \mathrm{~mm} / \mathrm{month}$, which explains the entry of the ground surface deformation into the last phase of stabilization (since 2006) [46].

Under the scenario of mining only panels P (3-4), P5, and P6 in coal seam number 3, a series of 2D and 3D finite element analyses were conducted and certain profile functions specific to this area were established, which are presented in the article [45]. Along with other subsidence measurements from the Jiu Valley basin, the subsidence measurements related to the profile from the Livezeni mine, which were carried out until 2009, were used to validate the models with 2D and 3D finite elements related to this profile and to calibrate the in situ geomechanical characteristics, which are used subsequently in the numerical models of building stability and will be analyzed in Section 3. These studies were conducted in two stages. In the first stage, based on several computational numerical models, a sensitivity analysis of the horizontal and vertical displacements was carried out on the variation of the geometric parameters of the goaf and the main in situ geomechanical properties of the rocks and coal. It was found that the elastic properties (in particular, the modulus of elasticity and Poisson's coefficient) 
have the greatest influence on the displacements. In the second stage of the study, using subsidence measurements from several mining fields in the Jiu Valley and their numerical simulation models, the in situ geomechanical properties were calibrated, which were used in all subsequent numerical models of ground surface analysis in the Jiu Valley.

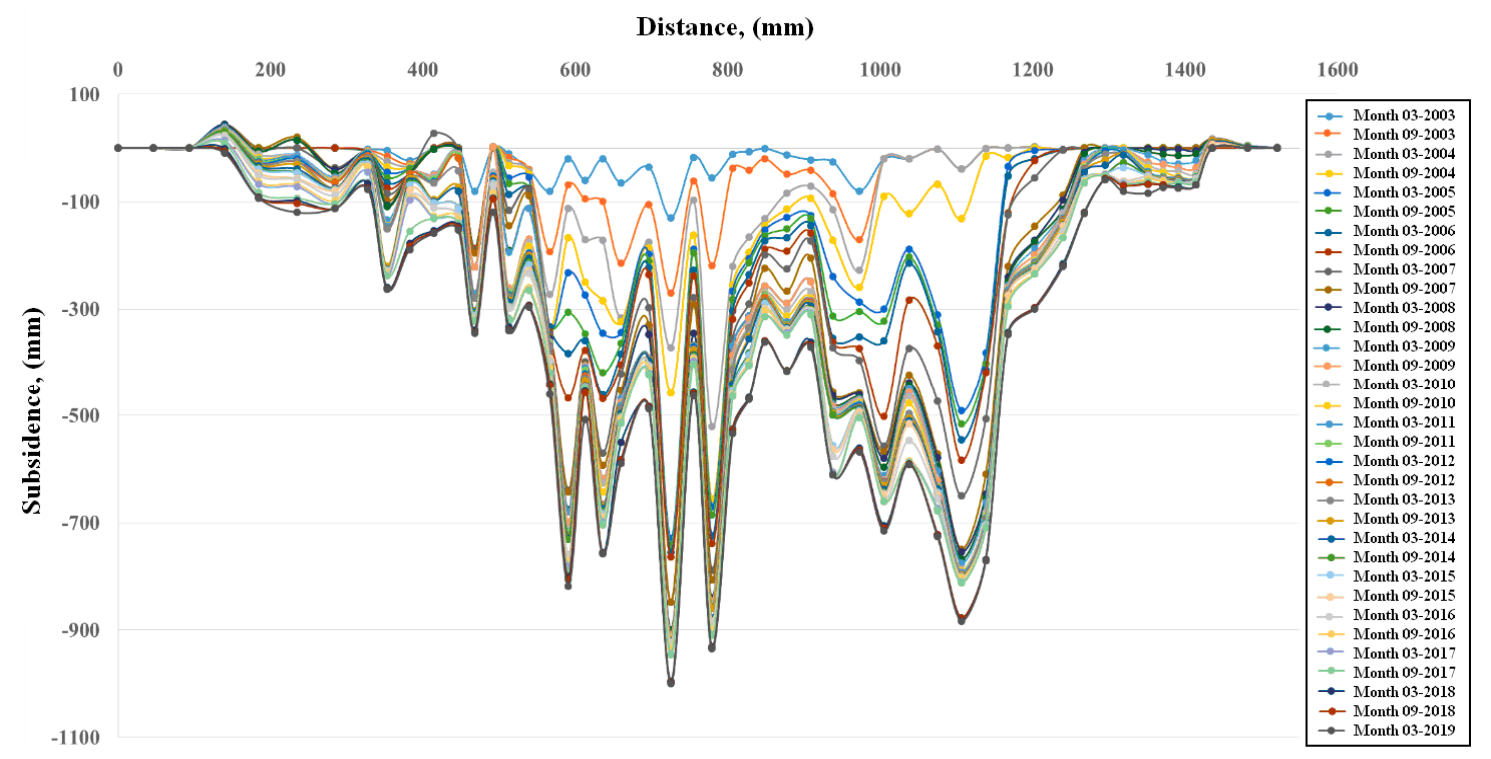

Figure 4. Subsidence curves developed over time at the Livezeni colliery (values measured in the period 2003-2019).

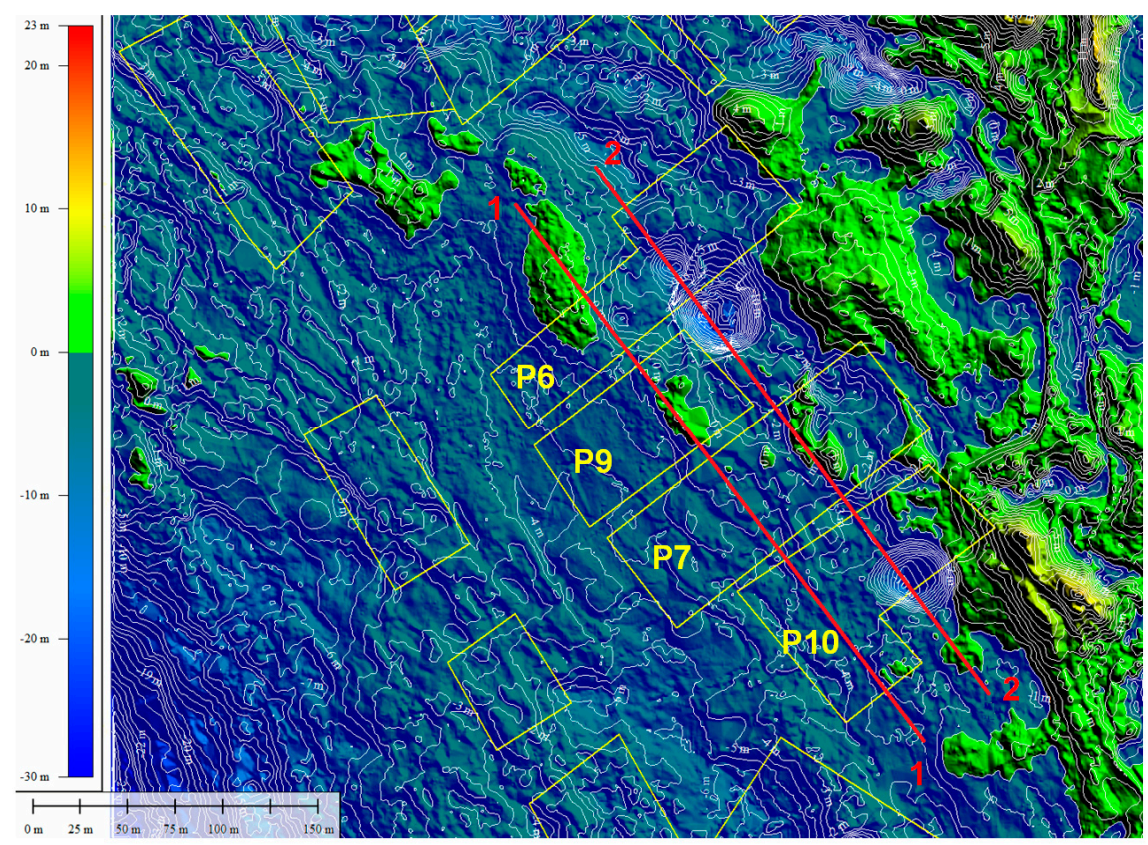

Figure 5. Ground subsidence during the period 1980-2017—scalar representation.

\subsection{The Case of the Lupeni Colliery}

In the Lupeni mining area, the exploitation of the coal deposit started with coal seam number 18 in 1960, continuing with coal seams numbers $15,14,13$, and then with coal seam number 5 , which ended the exploitation of the upper seams in 1989. Most coal seams have a thickness of about 2-3 m, and coal seam number 5 has a thickness of $7.5 \mathrm{~m}$. The duration of the mining of these coal seams until now has been 30 years for coal seam number 5, 34 years for coal seam number 13, and 39 years for the rest of the coal seams in the package. This leads to the conclusion that the caved rocks existing in the gobs of 
these coal seams had sufficient time to become compacted and the ground surface had time to become affected by the subsidence from reaching the tertiary or residual stabilization phases [47]. Therefore, the comparative analysis of the subsidence produced between 1980 and 2018, which is the object of this study, is significantly determined by the coal mining using top coal caving in longwall faces of thick coal seam number 3, which started in 2003 [6].

Having a comparative information base between the ground surface configuration in 1980 (taken from the drawings with level curves plotted by aerophotogrammetry) and one in 2017 (obtained by aerial laser scanning), it was possible to evaluate the subsidence of the land after a period of approximately 37 years. To achieve this goal, two digital elevation models (DEM) have been generated to obtain the total ground surface deformation for the mentioned time period, giving the differences between the two 3D models $[47,48]$.

For the assessment of the deformation of the ground surface, in the case of the Lupeni colliery during the period between 1980 and 2017, the elevation models of the previously realized surface elevation (for the years 1980 and 2017) were imported into the Global Mapper program, and then using the command "combine terrain layers", the two surfaces were combined, extracting only the differences between them. These differences represent the vertical displacement of the surface, shown in Figures 5 and 6, to which the SH3 sinkhole was added, which appeared later in 2018.

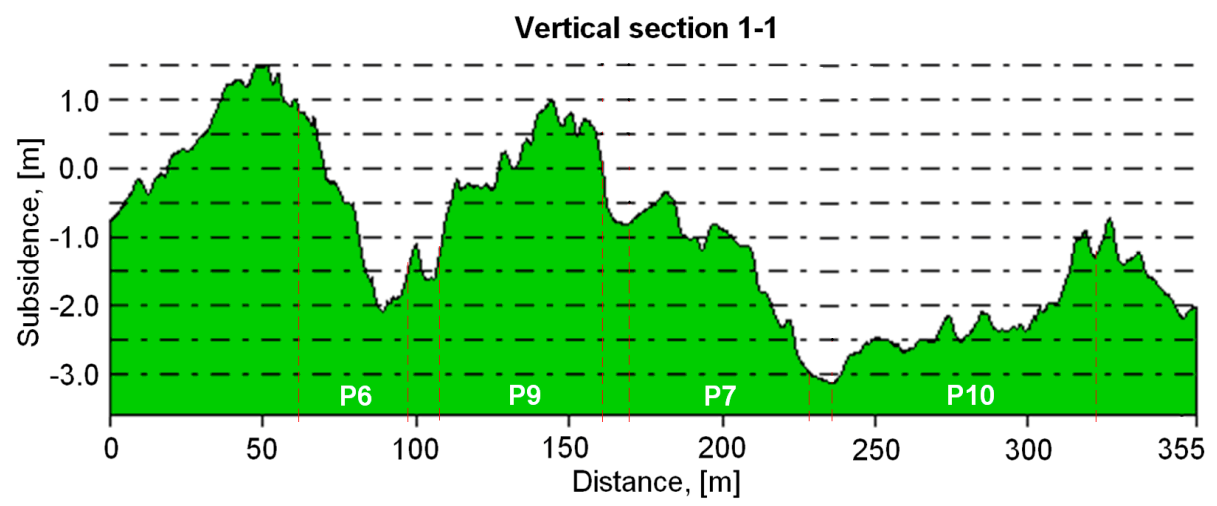

(a)

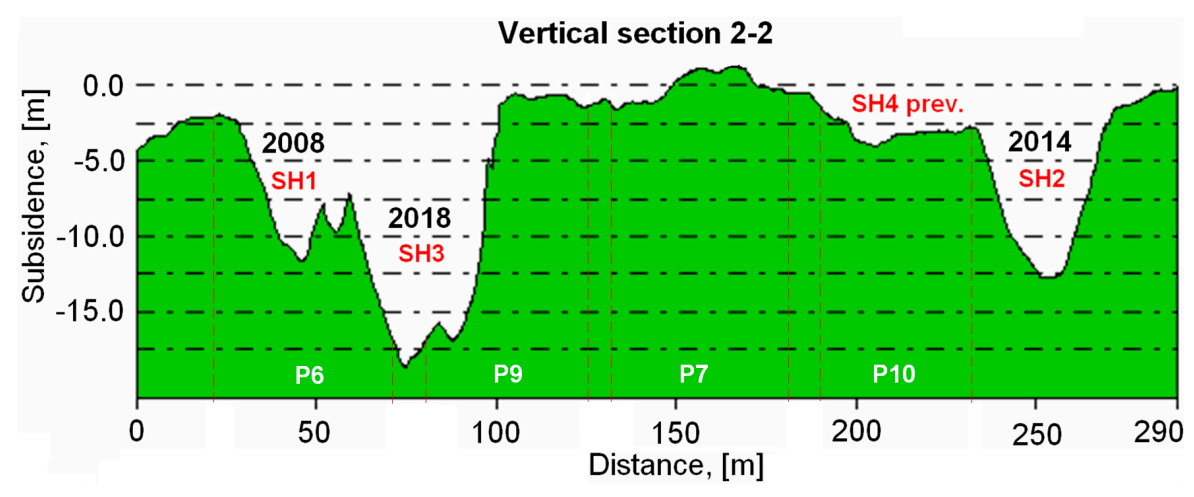

(b)

Figure 6. Subsidence on the alignments: (a) vertical cross-section 1-1 (panels P6, P9, P7, and P10); (b) vertical cross-section 2-2 (sinkholes $\mathrm{SH} 1, \mathrm{SH} 2, \mathrm{SH} 3$, and the subsidence terrace or predicted sinkhole SH4 preview).

The main geometrical characteristics of the panels located in the area containing sinkholes, which were mined with longwall top coal caving method, are shown in Table 2. 
The maximum subsidence produced during the period 1980-2017 in the middle of the panels, as determined from the plane in Figure 5, are between $1.4 \mathrm{~m}$ for the case of panel P9 and $6.0 \mathrm{~m}$ for panel P6.

Table 2. Main features of panels P6, P9, P7, and P10 in the area of coal seam number 3, block V, Lupeni.

\begin{tabular}{ccccc}
\hline Features & P6 & Panel & P7 & P10 \\
\hline Length of panel (m) & 180 & 104 & 170 & 124 \\
Length of longwall coal face (m) & $60 / 37$ & 53 & 60 & $50 / 87$ \\
Mining height, (m) & $12-15$ & $12-15$ & $12-15$ & $15-22$ \\
Mining depth, (m) & 265 & 275 & 265 & 242 \\
Mining period & 01.05 .2005 & 01.01 .2017 & 01.07 .2006 & 01.09 .2012 \\
& 01.03 .2010 & 08.05 .2019 & 01.06 .2009 & 01.02 .2015 \\
\hline
\end{tabular}

From section 1-1, the dimensions of the three sinkholes (depth of approximately $11 \div 19 \mathrm{~m}$ and diameter of $33 \div 52 \mathrm{~m}$ ) are shown, which are listed in ascending order as the number of panels used increases (the panels were extracted in the order of P6, P7, P10, and P9). This is explained by the successive increase of the state of stresses and deformations in the massif in the area of block $\mathrm{V}$ with the increase of the volume of coal extracted.

The behavior of the roof rock was greatly influenced by the use of the top coal caving longwall mining method, classic technology equipped with individual supports (consisting of articulated beams and hydraulic props), and the cutting of the coal face with a drilling-blasting system. The low advancement rate of the coal faces obtained with this technology, ranging between 5 and $14 \mathrm{~m} / \mathrm{month}$ (depending on the coal face length and the top coal height), greatly influenced the behavior of the top coal and roof rock, being one of the main factors that determines the occurrence of sinkholes.

\section{Study on the Behaviour of Buildings Located in the Influence Area of Thick Coal Seam Mining by 3D Finite Element Modelling}

\subsection{Description of Finite Element Models}

The purpose of the research constituting the subject of this paper is the study of the behaviour of buildings located on the ground surface of the coal deposits in the Jiu Valley, which are under the influence of thick coal seam mining with gentle dips using different extraction systems. In these geo-mining conditions, several numerical models were generated, which were the basis of the following stability analyses, namely:

(a) the stability of buildings with the same geometry in the horizontal plane, with one, two, and three levels, built entirely of reinforced concrete;

(b) the stability of a building with two levels of different lengths, the first version built entirely of reinforced concrete and another variant built with brick masonry walls and reinforced concrete floors.

We mention the fact that the modelled buildings are representative of the houses in the Jiu Valley, where the precast reinforced concrete buildings are predominant.

To achieve the purpose of the mentioned investigations, we used 3D finite element modelling with the aid of the CESAR-LCPC software version 4 and the CLEO3D processor.

From the beginning, we must highlight a series of constraints and limits imposed by the complexity of the aforementioned models, namely:

- $\quad$ the very large dimensions of the models $\left(0.5\right.$ billion $\left.\mathrm{m}^{3}\right)$, determined by the large volume of the gobs, which require significant computational resources;

- the very high ratio between the relatively small sizes of the buildings and the very large dimensions of the modelled rock massif; 
- $\quad$ the important number of models (over of 300 computational models) with different geometries (determined by the existence of panels in different mining sequences and buildings of different lengths and heights) coming from a single conceptual 3D finite element model.

Due to the above restrictions, in order for these models to be put into operation, it was necessary to implement the following simplifications, without inducing significant deviations in the results obtained:

- $\quad$ focusing the modelling interest on the behaviour of buildings and less on the behaviour of the ground surface, in the context of sequential extraction of a coal seam;

- $\quad$ the thick coal seam undergoing exploitation is modelled as horizontal;

- the gobs are represented in the massif model in the form of voids;

- the coal seam, the rock mass, and the constructive elements of buildings are considered to be continuous, homogeneous, and isotropic;

- $\quad$ the rock massif loading is simulated as gravitational.

We mention that the above simplifications were performed based on sensitivity analyses of the main parameters of the subsidence troughs to the variation of the geometrical and qualitative characteristics contained in the analyzed models, and the calculation parameters were calibrated according to the in situ ground deformation measurements [45,49].

As a consequence, the modelling of the coal deposit subjected to mining was made for the conditions of thick coal seams with gentle dips, located at an average depth of $H=300 \mathrm{~m}$-the most frequently encountered depth of thick coal seam number 3 in the areas with reduced dips in the Jiu Valley hard coal basin (for example, from the Paroşeni, Lupeni, and Livezeni mining fields, shown in Figure 1).

So that the results obtained can be significant for the conditions in the Jiu Valley, the coal seam was imagined as being mined in a panel with a total extension of $X_{p}=400 \mathrm{~m}$ and with a longwall face length of $l_{f}=150 \mathrm{~m}$. We note that due to the complicated tectonics of the coal field in the Jiu Valley, these dimensions of the panels are technically possible.

In the finite element analysis, several case studies were considered for the mined coal seams with longwall coal faces:

(a) the caving of the roof rocks (Figure 7a) of a coal seam mined at mining heights of $h_{e x}=3 \mathrm{~m}, 4 \mathrm{~m}$, and $5 \mathrm{~m}$;

(b) top coal caving (Figure $7 \mathrm{~b}$ ) of a coal seam mined at a mining height of $h_{e x}=9 \mathrm{~m}$.

(c) Regarding the modelling of the stability of the structures on the surface, two fundamental situations were analyzed:

(a) buildings with a fixed horizontal surface ( $\left.X_{\text {building }}=20 \mathrm{~m} / Y_{\text {building }}=10 \mathrm{~m}\right)$, with one, two, and three levels (with $Z_{\text {building }}=3 \mathrm{~m}, 6 \mathrm{~m}$, and $9 \mathrm{~m}$ high) and with coal seam mining heights of $h_{e x}=3 \mathrm{~m}, 4 \mathrm{~m}$. and $9 \mathrm{~m}$ (where: $X_{\text {building, }}, Y_{\text {building }}$ and $Z_{\text {building }}$ are the dimensions of the buildings);

d) buildings with two levels (with a height of $Z_{\text {building }}=6 \mathrm{~m}$ ), with a constant width $\left(Y_{\text {building }}=18 \mathrm{~m}\right.$ ) and variable length $\left(X_{\text {building. }}=50 \mathrm{~m} \div 100 \mathrm{~m}\right.$ ) and with a coal seam mining height of $h_{e x}=5 \mathrm{~m}$.

The buildings were arranged on the vertical line raised in the center of the panel (for $X_{p}=400 \mathrm{~m}$ ). In all cases, the levels of buildings with a height of $3 \mathrm{~m}$ were separated from each other with reinforced concrete floors, so that a series of buildings with heights of $3 \mathrm{~m}, 6 \mathrm{~m}$, and $9 \mathrm{~m}$ resulted in the image shown in Figure 8).

As we can see in Figure 9, the computational models studied the successive mining of the panel in several stages, starting from the set up room at point A to the recovery room at point $\mathrm{B}$. 


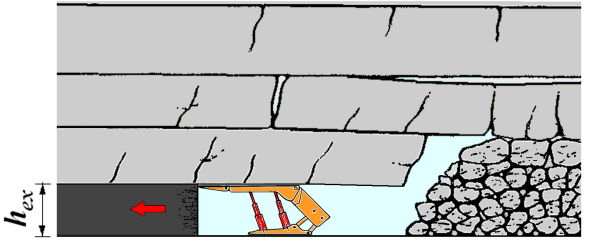

(a)

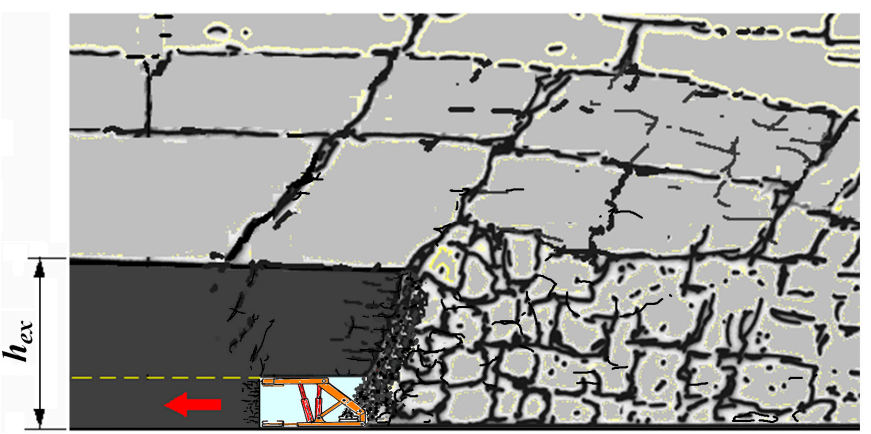

(b)

Figure 7. Longwall mining face: (a) ith caving of the roof rocks (modified from Peng [36]); (b) with top coal caving (not to scale).

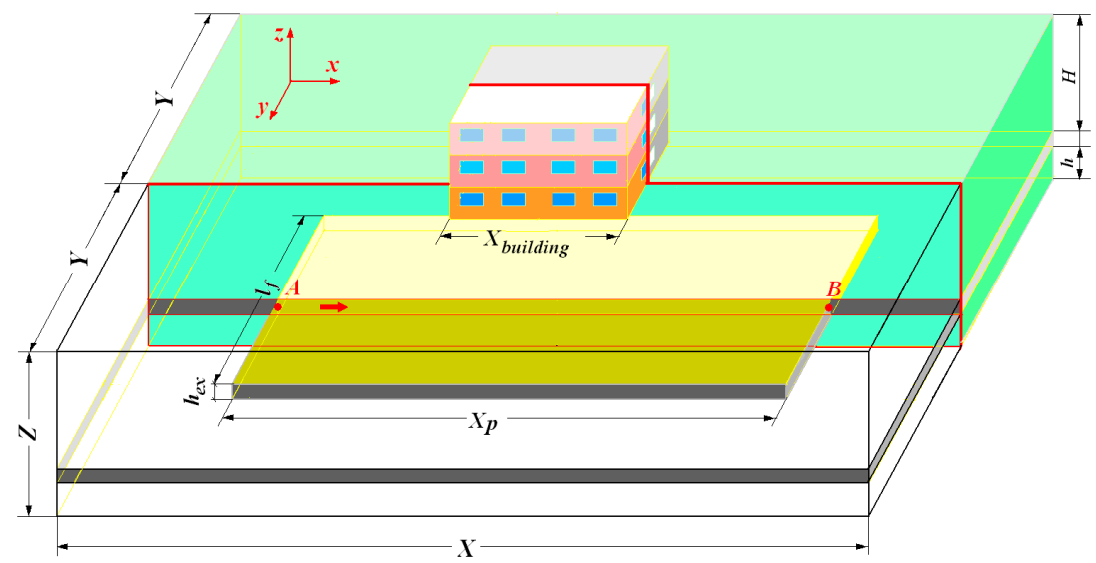

Figure 8. Principle diagram of the symmetrical 3D finite element model used to analyze the influence of the mining of a thick coal seam with a gentle dip on a building (not to scale). $X, Y, Z=$ model dimensions; $H=$ mining depth; $h_{e x}=$ coal seam mining height; $h=$ distance from the coal seam to the model lower limit; $X_{p}=$ panel extension; $l_{f}=$ length of the longwall face; $X_{\text {building }}=$ building length.
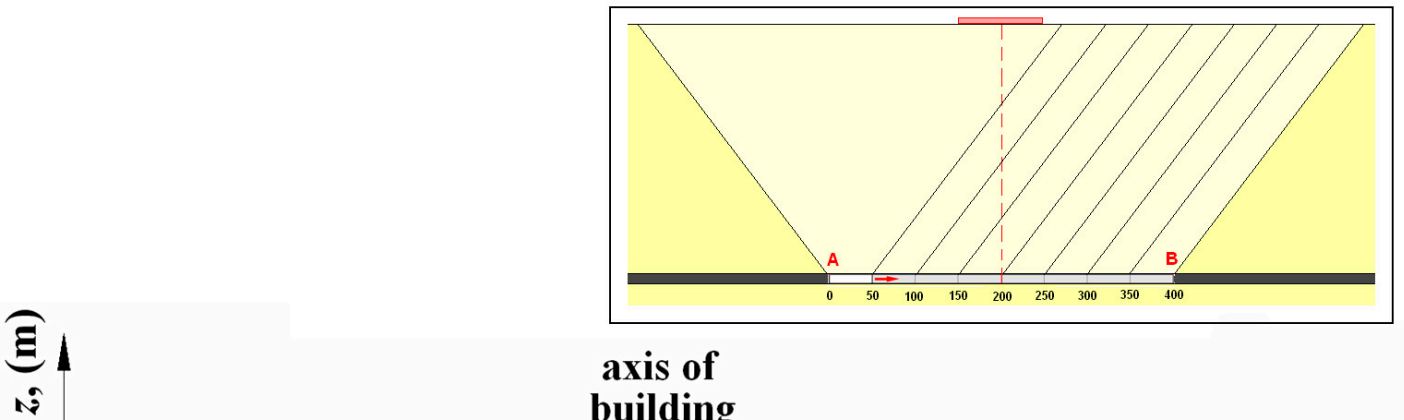

axis of

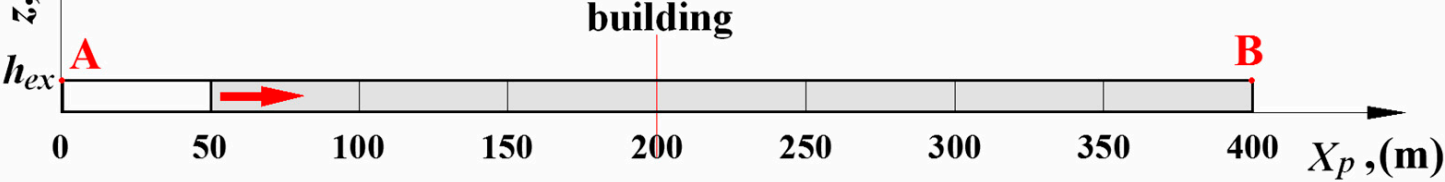

Figure 9. Panel mining sequences (not to scale).

In order to reduce the dimensions of the basic model (see Figure 7), its symmetry was taken into account according to the vertical cross-section plane $z 0 x$, resulting in a model with dimensions of $X=2500 \mathrm{~m}, Y=500 \mathrm{~m}$, and $Z=400 \mathrm{~m}$, with a total volume of modelled rock massif of $500 \times 10^{6} \mathrm{~m}^{3}$. The models with finite elements were meshed with 40,843 volumetric finite elements, 540 surface finite elements (shell type), and 23,712 nodes. 
The density of discretization with finite elements is increased near the foundation of the buildings and around the excavations, where the variation of strains and stresses is more pronounced.

Regarding the representation of the massif, this was obtained from the discretization in the plane of a model with triangular finite elements, and through its sequential "extrusion" after the " $z$ " axis, 3D finite elements in the form of triangular prisms were obtained with the height oriented after this axis.

Due to the very large volume of the modelled rock massif, which requires significant computational resources, in order to reduce them for the construction of the walls and floors of the modelled buildings, the "extrusion" option of the CLEO3D processor was used, but applied on linear finite elements in order to generate "shell" surface finite elements.

For the implementation of the model boundary conditions, the following restrictions were imposed. For the lower limit, the movement along the $z$ axis was blocked $\left(U_{x}=U_{y} \neq 0 ; W_{z}=0\right)$, and for the lateral limits, the movements along the $x$ and $y$ axes $\left(U_{x}=U_{y}=0 ; W_{z} \neq 0\right)$ maintained the freedom of movement for the ground surface $\left(W_{z} \neq 0\right)$.

Regarding the constitutive laws of the materials used in the models, a hypothesis incorporating an elasto-plastic Mohr-Coulomb criterion without hardening behaviour for the rock or coal mass was used; and an elastic type was chosen for the reinforced concrete and masonry construction elements. In this regard, we adopted average features determined in the laboratory and in situ for the rock and coal mass, which are presented in Table 3. The properties of real rock masses in the field are usually different from those tested in the laboratory [50]. Therefore, following the sensitivity analyses of the parameters according to different factors, performed on numerical models [49] and calibrated on in situ measurements, the characteristics of the massif used in numerical modelling were adopted [45]. The elastic modulus, cohesion, and tensile strength results are generally $0.1-0.25$ of the laboratory testing results. The Poisson's ratios are approximately 1:2-1:4 of the laboratory testing results [51].

Table 3. The average physical-mechanical and elastic properties of the surrounding rocks and hard coal seam number 3.

\begin{tabular}{|c|c|c|c|c|c|c|}
\hline Properties & Rocks & $\begin{array}{l}\text { Density } \\
\left(\mathrm{kg} / \mathrm{m}^{3}\right)\end{array}$ & $\begin{array}{c}\text { Young's Modulus } \\
\text { of Elasticity } \\
\left(\mathrm{kN} / \mathrm{m}^{2}\right)\end{array}$ & $\begin{array}{l}\text { Poisson's } \\
\text { Ratio }\end{array}$ & $\begin{array}{l}\text { Cohesion } \\
\left(\mathrm{kN} / \mathrm{m}^{2}\right)\end{array}$ & $\begin{array}{c}\text { Internal } \\
\text { Friction Angle } \\
\left({ }^{\circ}\right)\end{array}$ \\
\hline \multirow[t]{2}{*}{ In laboratory } & $\begin{array}{l}\text { Rocks from the floor } \\
\text { and roof }\end{array}$ & 2660 & $5.2 \times 10^{6}$ & 0.19 & $6.5 \times 10^{3}$ & 54 \\
\hline & Coal seam number 3 & 1450 & $1.04 \times 10^{6}$ & 0.14 & $1.5 \times 10^{3}$ & 40 \\
\hline \multirow{2}{*}{$\begin{array}{c}\text { In situ } \\
\text { (in massif) }\end{array}$} & $\begin{array}{l}\text { Rocks from the floor } \\
\text { and roof }\end{array}$ & 2660 & $1.2 \times 10^{6}$ & 0.26 & $1.6 \times 10^{3}$ & 54 \\
\hline & Coal seam number 3 & 1450 & $0.2 \times 10^{6}$ & 0.19 & $0.3 \times 10^{3}$ & 40 \\
\hline
\end{tabular}

For the materials used in the structural elements of the structures modelled with finite element method, a series of equivalent average properties were adopted, both for reinforced concrete and for the masonry walls (zigzag bricks and mortar [23]), shown in Table 4.

Table 4. Equivalent physical-mechanical and elastic properties of construction materials.

\begin{tabular}{|c|c|c|c|c|c|}
\hline Building Material & $\begin{array}{l}\text { Density } \\
\left(\mathrm{kg} / \mathrm{m}^{3}\right)\end{array}$ & $\begin{array}{c}\text { Young's Modulus } \\
\text { of Elasticity } \\
\left(\mathrm{kN} / \mathrm{m}^{2}\right)\end{array}$ & $\begin{array}{l}\text { Poisson's } \\
\text { Ratio }\end{array}$ & $\begin{array}{l}\text { Compressive } \\
\text { Strength } \\
\left(\mathrm{kN} / \mathrm{m}^{2}\right)\end{array}$ & $\begin{array}{c}\text { Tensile } \\
\text { Strength } \\
\left(\mathrm{kN} / \mathrm{m}^{2}\right)\end{array}$ \\
\hline Reinforced concrete & 2500 & $30 \times 10^{6}$ & 0.2 & 16,000 & 1200 \\
\hline Brick walling & 2000 & $1 \times 10^{6}$ & 0.2 & 5500 & 350 \\
\hline
\end{tabular}

In the calculations, "phase" loading of the model was used, using the MCNL module of the CESAR solver. The model was geostatically loaded in the initial phase, with average vertical stresses at the mining level $\sigma_{z}=\gamma_{r} \cdot H=8 \mathrm{MN} / \mathrm{m}^{2}$ and horizontal stresses $\sigma_{x}=\sigma_{y}=k_{o x} \cdot \sigma_{z}=k_{o y} \cdot \sigma_{z}=2 \mathrm{MN} / \mathrm{m}^{2}$; the buildings were gravitationally charged. Here, $\gamma_{r}$ is the average apparent specific weight of the 
overburden rocks; $k_{o x}=k_{o y}=v /(1-v)$ [52]; $v=0,2$ is the average Poisson's ratio (represents the value of the weighted arithmetic mean of all the rock strata in the package, depending on their thickness).

\subsection{Deformation of the Ground Surface due to Underground Mining}

Following the calculations made on the finite element models, different values were obtained for subsidence $W_{z}$ and horizontal displacement $U_{x}$ of the ground surface, depending on the coal seam mining height $h_{e x}$, the position of the coal working face, and the mining extension of panel $X_{p}$.

For example, for the coal seam with a mining height of $h_{e x}=5 \mathrm{~m}$, the subsidence $W$ reaches a maximum value of $+2400 \mathrm{~mm}$ at the time of full operation of the panel with a length of $X_{p}=400 \mathrm{~m}$, and at the point where the gob has an extension of the mined out area measuring $X_{p}=50 \mathrm{~m}$, the subsidence is $140 \mathrm{~mm}$ (Figure 10a).

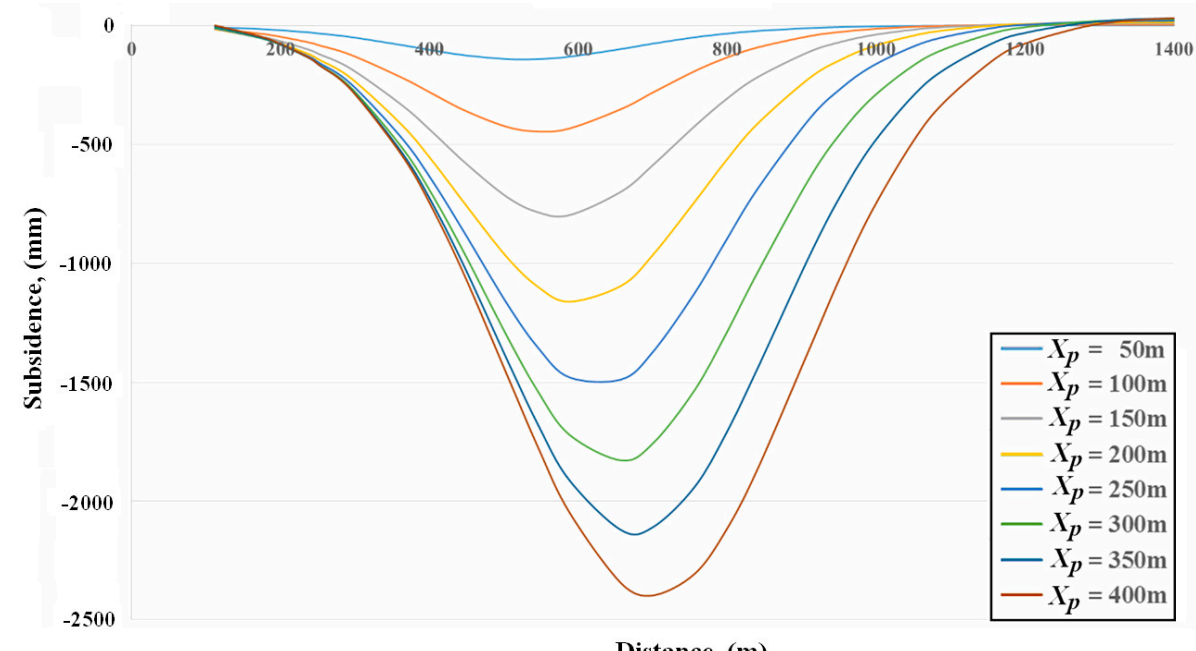

(a)

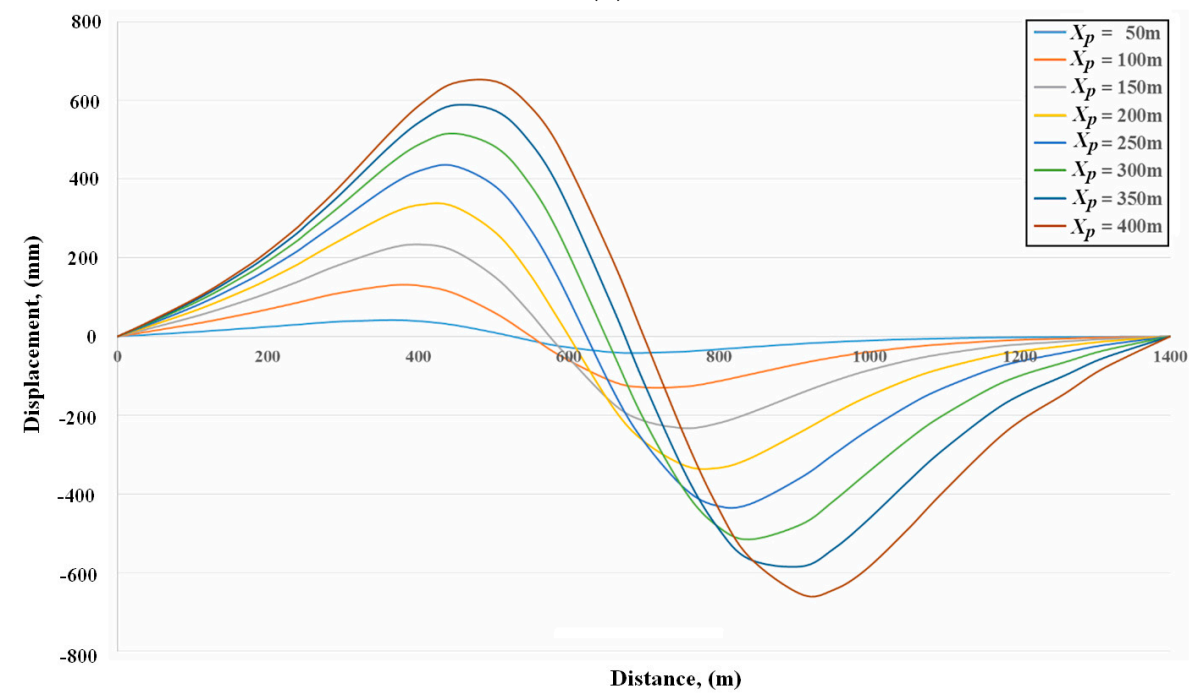

(b)

Figure 10. Evolution of subsidence $W_{z}(\mathbf{a})$ and of horizontal displacement $U_{x}(\mathbf{b})$ for $h_{e x}=5 \mathrm{~m}$, along with the advance of the working face.

The horizontal displacement $U_{x}$ at the point where the mined panel has a size of $X_{p}=50 \mathrm{~m}$ and is at a distance of $150 \mathrm{~m}$ from the axis of the building, it has a maximum value of $\pm 42 \mathrm{~mm}$. It continues its development until the full exploitation of the panel, where it reaches a value of $\pm 657 \mathrm{~mm}$ (Figure 10b). 
For all cases analyzed with finite elements, the maximum values of the ground surface displacement parameters are summarized in Table 5.

Table 5. The maximum vertical and horizontal displacements values $W_{\max }$ and $U_{x}$ max and results from the finite element analysis on elasto-plasticity for $X_{p}=400 \mathrm{~m}$.

\begin{tabular}{ccccc}
\hline Parameter & $\boldsymbol{h}_{\boldsymbol{e x}}=\mathbf{3} \mathbf{~}$ & $\boldsymbol{h}_{\boldsymbol{e x}}=\mathbf{4} \mathbf{~}$ & $\boldsymbol{h}_{\boldsymbol{e x}}=\mathbf{5} \mathbf{~ m}$ & $\boldsymbol{h}_{\boldsymbol{e x}}=\mathbf{9} \mathbf{~}$ \\
\hline$W_{\max },(\mathrm{mm})$ & +1440 & +1920 & +2400 & +4320 \\
$U_{x \max },(\mathrm{mm})$ & \pm 394 & \pm 526 & \pm 657 & \pm 1183 \\
\hline
\end{tabular}

3.3. Analysis of the Distribution of the Principal Stresses in the Structural Elements of the Buildings from the Jiu Valley

The stability analysis of the buildings under study, modelled with "shell" finite elements, is performed based on the distribution of the major principal stress $\sigma_{1}$ and minor stress $\sigma_{3}$ in the structure of the modelled buildings. The assessment of the behaviour of the structural elements of the buildings and the requests determined by the principal stress is based on "the theory of maximum normal stress", which is applicable, but with a bias for brittle or rigid materials (such as concrete and brick masonry). Based on this theory, the limited state of strength of the material at one point of the resistance element is reached when the value of the major principal stress $\sigma_{1}$ or minor stress $\sigma_{3}$ is equal with to limit strength (stress) in the tensile test $R_{t}$ or simple compressive test $R_{c}$ of the respective material.

\subsubsection{Analysis of Stresses in Buildings with One, Two, and Three Levels}

\section{Single-Level Buildings}

In the case of buildings with one level, the development of maximum values of the major principal stress $\sigma_{1}$ is for tensile ranges between $1640 \mathrm{kN} / \mathrm{m}^{2}$ and $31,800 \mathrm{kN} / \mathrm{m}^{2}$ for $h_{e x}=3 \mathrm{~m}$; and between $1840 \mathrm{kN} / \mathrm{m}^{2}$ and $33,100 \mathrm{kN} / \mathrm{m}^{2}$ for $h_{e x}=9 \mathrm{~m}$ (Figure 11).

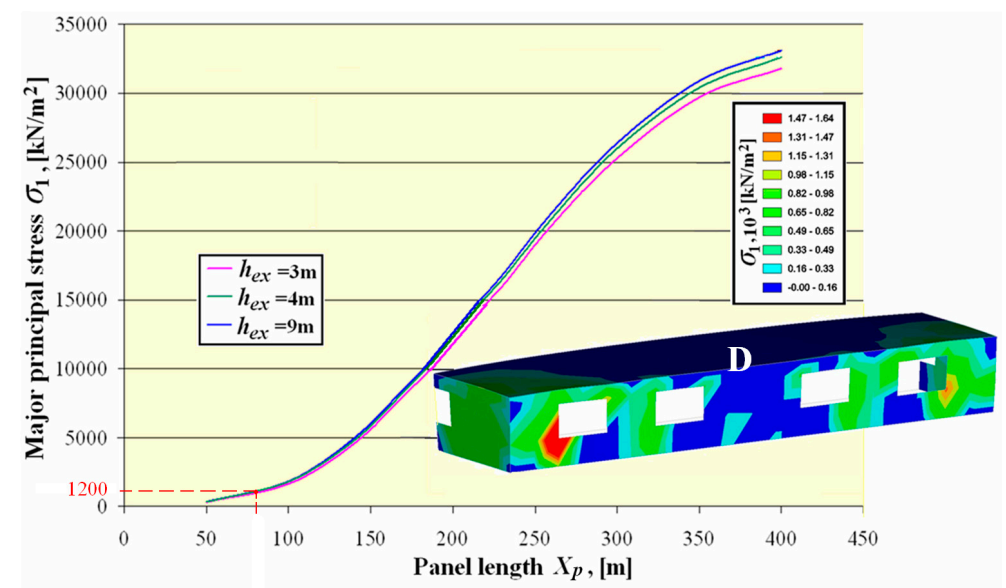

Figure 11. Development of maximum values of major principal stress $\sigma_{1}$ in the structure of a single-level building (detail D for $h_{e x}=3 \mathrm{~m} ; X_{p}=100 \mathrm{~m}$ ).

Regarding the development of maximum stresses in the building, depending on the mined thickness of the coal seam hex, there is a concentration of tensile stresses on the floor, the corners of the windows, and the walls of the building closest to the coal face line when the working face is in the second sequence of the model for $X_{p}=100 \mathrm{~m}$. The extension of the zones affected by the coal mining continues so that at the end of the exploitation of the coal seam, the areas where the highest concentration of stresses exists are the corners of the windows; the joints between the side walls, the front walls, and the floor of the building; the part of the wall between the windows; and the window lintels (Figure 11, detail D). 
Following the analysis of the maximum values of minor principal stresses $\sigma_{3}$ (compressive stresses) developed in the structural elements of a single-level building (Figure 12), it turns out that they occur from a value of $-7000 \mathrm{kN} / \mathrm{m}^{2}$ for $h_{e x}=3 \mathrm{~m}$ and $X_{p}=100 \mathrm{~m}$ down to a value of $-80,800 \mathrm{kN} / \mathrm{m}^{2}$ when fully operating the panel (for $X_{p}=400 \mathrm{~m}$ ).

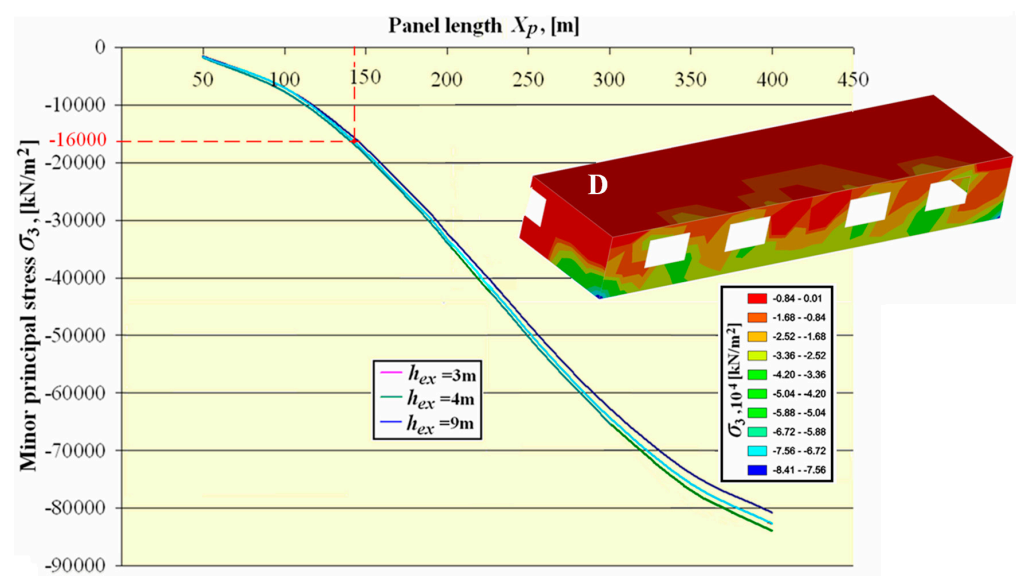

Figure 12. The evolution of maximum values of minor principal stress $\sigma_{3}$ in the structure of a single-level building (detail D for $h_{e x}=9 \mathrm{~m} ; X_{p}=400 \mathrm{~m}$ ).

In the case of the mining panel with $X_{p}=100 \mathrm{~m}$, the main structural elements of the building loaded by compressive stresses are the foundation, the window parapet, and the part of the building closest to the coal face line. Consequently, the degradation of the building continues so that at the end of the operation of the panel, the building is totally affected, with the most affected areas being the corners of the windows, the joints between the side walls, the front walls, and the foundation (Figure 12, detail D).

\section{Two-Level Buildings}

Regarding the major principal (tensile) stress $\sigma_{1}$, to which a building with two levels is exposed, for $h_{e x}=9 \mathrm{~m}$ and $X_{p}=400 \mathrm{~m}$, a maximum of $32,700 \mathrm{kN} / \mathrm{m}^{2}$ is reached, so that the following are subject to tensile stresses: the facade and the lower and upper corners of the windows on the two levels of the building; and the area where the facade of the building joins with the side walls, both on the first level and the higher level (Figure 13a).

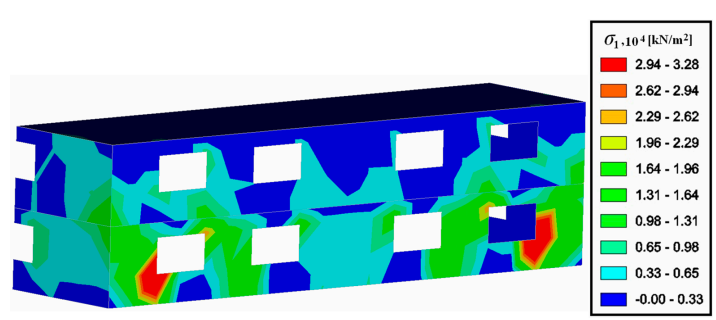

(a)

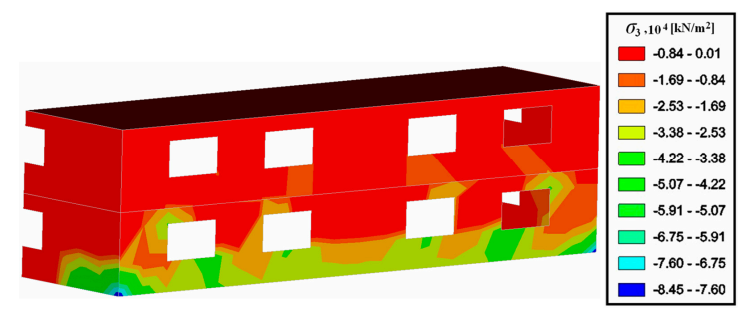

(b)

Figure 13. The scalar representation of the principal stresses in a two-level building for $h_{e x}=9 \mathrm{~m}$, and a panel extension of mining $X_{p}=400 \mathrm{~m}$ : (a) major principal stresses $\sigma_{1}$; (b) minor principal stresses $\sigma_{3}$.

For the same conditions, the value of the minor principal stress $\sigma_{3}$ (compressive stresses) reaches a maximum of $-84,400 \mathrm{kN} / \mathrm{m}^{2}$. The main areas of the building subject to compressive stresses (Figure 13b) are: the foundations as a whole, the parapets of the windows, the upper corners of the windows, the floor on the first level, and the parapets of the windows on the second level.

It should be noted that tensile or compressive loadings are focused on the first level, including its floor, and less so on the second level, whose floor is loaded insignificantly. 
Three-Level Buildings

Major principal (tensile) stresses $\sigma_{1}$ appearing in a building with three levels are influenced by the exploitation of a coal seam or $3 \mathrm{~m}$ slices and range between $1650 \mathrm{kN} / \mathrm{m}^{2}$ and $31700 \mathrm{kN} / \mathrm{m}^{2}$, growing to a maximum of $33,000 \mathrm{kN} / \mathrm{m}^{2}$ for $h_{e x}=9 \mathrm{~m}$.

In the case of extraction of a coal seam or slice with $h_{e x}=9 \mathrm{~m}$, for a mined panel measuring $400 \mathrm{~m}$, the main areas affected by major principal (tensile) stresses are: the building's front and the lower and upper corners of the windows from the first two levels of the building; the area where the facade of the building joins with the side walls, both on the first level and the upper level; and the side walls of the building, both on the first level and the other two upper levels (Figure 14a).

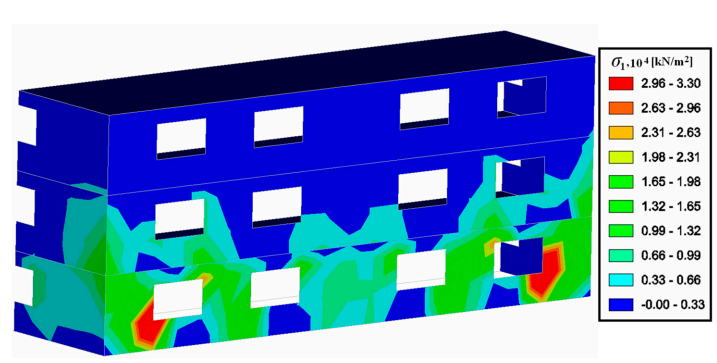

(a)

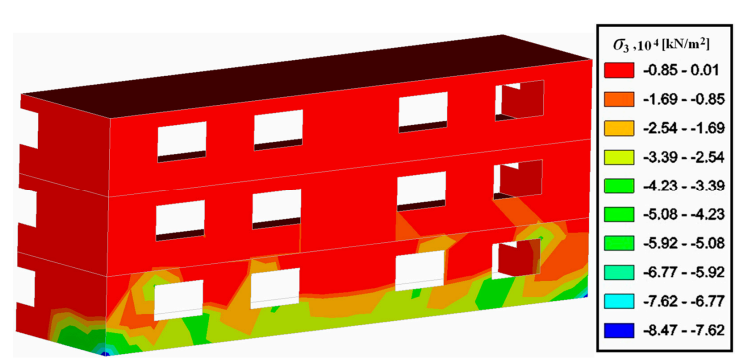

(b)

Figure 14. The principal stress distribution in the structure of a three-level building under the influence of underground mining for $h_{e x}=9 \mathrm{~m}$ and $X_{p}=400 \mathrm{~m}$ : (a) major principal stresses; (b) minor principal stresses.

The development of minor principal stresses $\sigma_{3}$ (compressive stresses) in the structural elements of the three-level building for $h_{e x}=3 \mathrm{~m}$ ranges between $-6950 \mathrm{kN} / \mathrm{m}^{2}$ and $-81,400 \mathrm{kN} / \mathrm{m}^{2}$, reaching a maximum of $-85,000 \mathrm{kN} / \mathrm{m}^{2}$ for $h_{e x}=9 \mathrm{~m}$.

These principal compressive stresses develop with the mining thickness of the coal seam, so that for $h_{e x}=9 \mathrm{~m}$ the main affected areas of the building are: the foundation as a whole; the parapets of the windows; the upper and lower corners of the windows; the floor from the first level and parts of the parapets of the windows from the second level; the area where the facade of the building joins with the side walls; and the foundation (Figure 14b).

As we can see from Figure 14, stress concentration is still mainly limited to the first level of the building; it is much less apparent on the second level and insignificant on the third level.

\subsubsection{Stress Analysis in Buildings with Two Levels and Different Lengths}

\section{Reinforced Concrete Buildings}

For reinforced concrete buildings, studying the results obtained by numerical modelling leads to an observation that the greatest stresses appear for a building with a length of $100 \mathrm{~m}$, with an extension of the mined out area measuring $X_{p}=400 \mathrm{~m}$. Principal stresses grow almost linearly in line with the length of the building and approximately linearly in three different areas in line with the development of the panel operation $X_{p}$.

As the length of the gob increases, stresses arising in the structures of the buildings start from an asymmetrical distribution with $X_{p}=50 \mathrm{~m}$ and reach an integral symmetrical distribution with respect to the building axis at the end of the panel extraction for $X_{p}=400 \mathrm{~m}$. In the latter case, the areas with the highest concentration of stresses are the corners of the foundations at the ends of the buildings and the upper corners of the windows.

The asymmetric distribution of stresses is given by the distance of the building from the working face and implicitly from the gob, which influences the spatial distribution of stress concentrators in the structure of the building, both in position and intensity. 
In the case of buildings with walls and floors made entirely of reinforced concrete, it is the case that the structural elements are very compact and the loads developed by the ground surface are transmitted almost entirely to the walls, which have very high bending rigidity. For this reason, one can notice a concentration of stresses in the hollows of the windows and towards the ends of the buildings.

Along with the increase of the volume of the gob area, it is evident that the displacements of the ground surface are amplified, causing an increase of stresses in the structural elements of the buildings. Moreover, we can observe a concentration of stresses towards the ends of the building, with their emphasis towards the end-facing the gob. These laws are general for distribution in the structure of buildings of different lengths with all types of stresses (which will be analyzed below).

In Figure 15, one may notice that the values of major principal (tensile) stresses $\sigma_{1}$ grow almost linearly as the length of the building increases in the range of 50-70 m, with a slow reduction of stress values for buildings over $70 \mathrm{~m}$ in length, reaching a maximum value for buildings measuring $100 \mathrm{~m}$ in length.

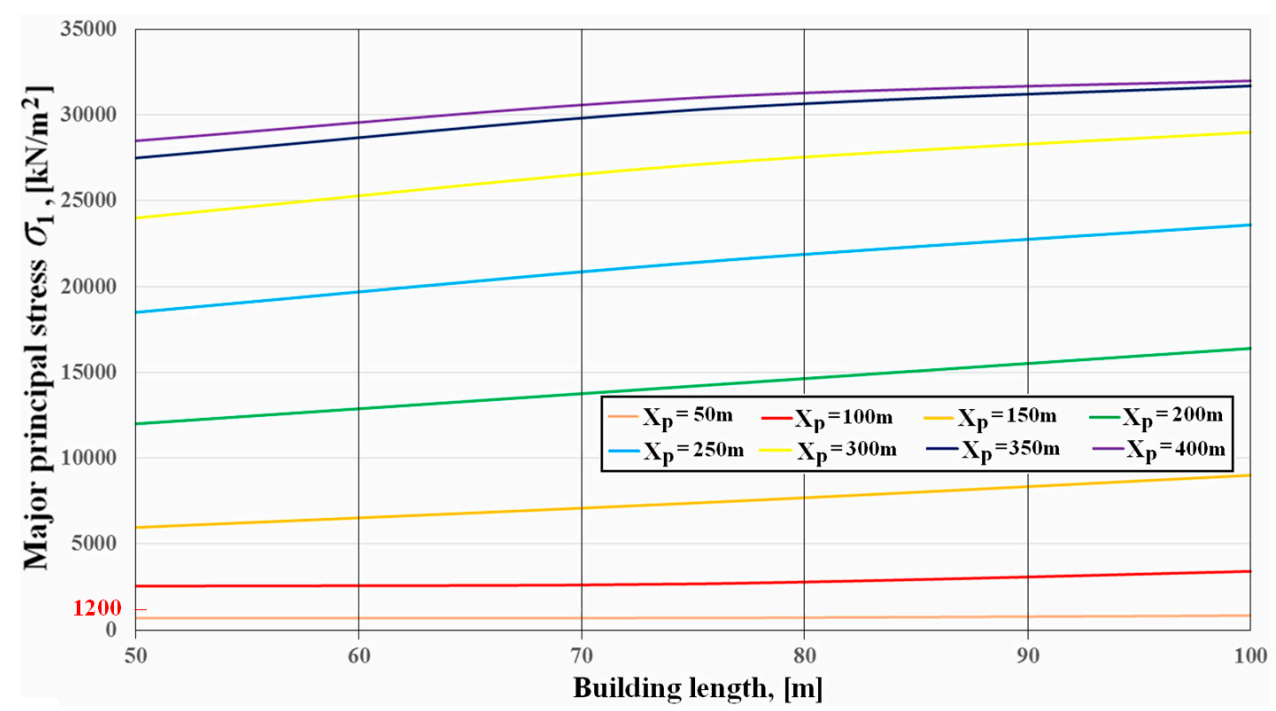

Figure 15. Evolution of the maximum values of major principal stresses $\sigma_{1}$ for reinforced concrete buildings, depending on the length of the building.

Depending on the mining extent of the panel, the dynamics of the maximum and minimum stresses have the same growth tendency, as shown in the previous subchapter (Section 3.3.1).

For all cases, it is observed that maximum stresses exceed the average tensile strength of the concrete (of $1200 \mathrm{kN} / \mathrm{m}^{2}$ ) immediately after the first operating sequence for $X_{p}=50 \mathrm{~m}$.

From the maximum stress distribution in the structure of the buildings, it is found that once the operation is started (for $X_{p}=50 \mathrm{~m}$ ), the most affected areas are the lower corner of the window on the long side of the building closest to the gob and the corner of the foundation opposite to it (Figure 16). After the operation reaches the final stage (under the conditions analyzed, $X_{p}=400 \mathrm{~m}$, with the building located in the center of the gob), it is found that major principal stresses reach the highest values in the lower corners of the marginal windows on the lower floor, with a decrease of the stress values towards the center of the buildings.

It should be noted that for all the cases analyzed, during the mining extension of the panel from $X_{p}=50 \mathrm{~m}$ to $X_{p}=400 \mathrm{~m}$ the development of major and minor stresses begins with a strongly asymmetrical distribution in relation to the length of the buildings towards their ends, which is accentuated towards the end closest to the gob area, which obviously reaches perfect symmetry at the end of the panel operation.

In the case of reinforced concrete buildings, the maximum values of minor principal stresses (Figure 17) show an increase in absolute value, which is approximately linear according to the lengths 
of the buildings (from the buildings with length of $50 \mathrm{~m}$ to those with lengths of $100 \mathrm{~m}$ ) for all operating sequences (between $X_{p}=50 \mathrm{~m}$ and $X_{p}=400 \mathrm{~m}$ ).

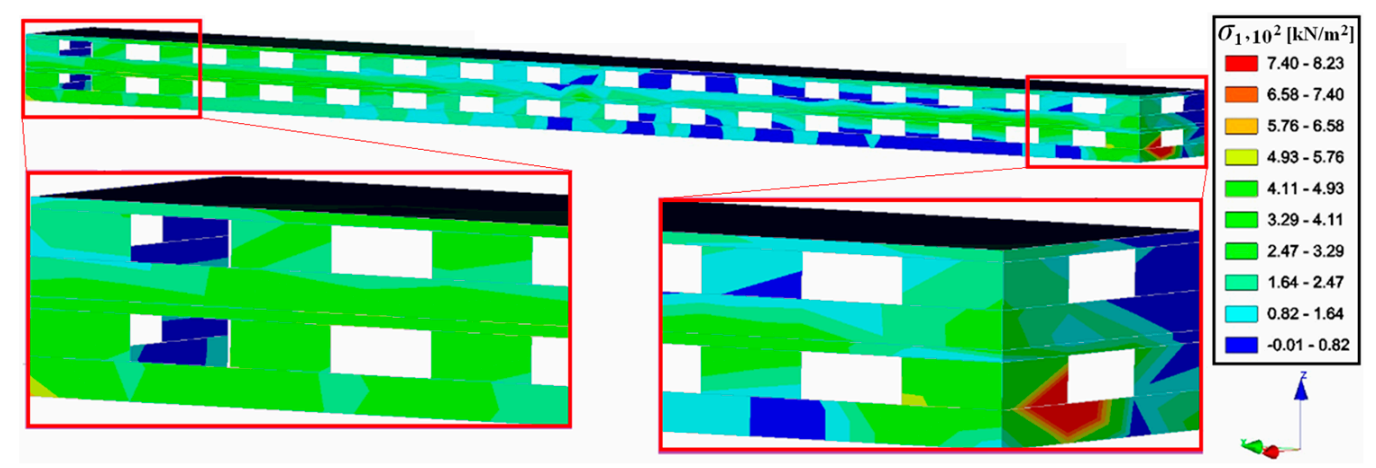

Figure 16. Distribution of major principal stresses $\sigma_{1}$ for a reinforced concrete building with a length of $100 \mathrm{~m}$ for $X_{p}=50 \mathrm{~m}$.

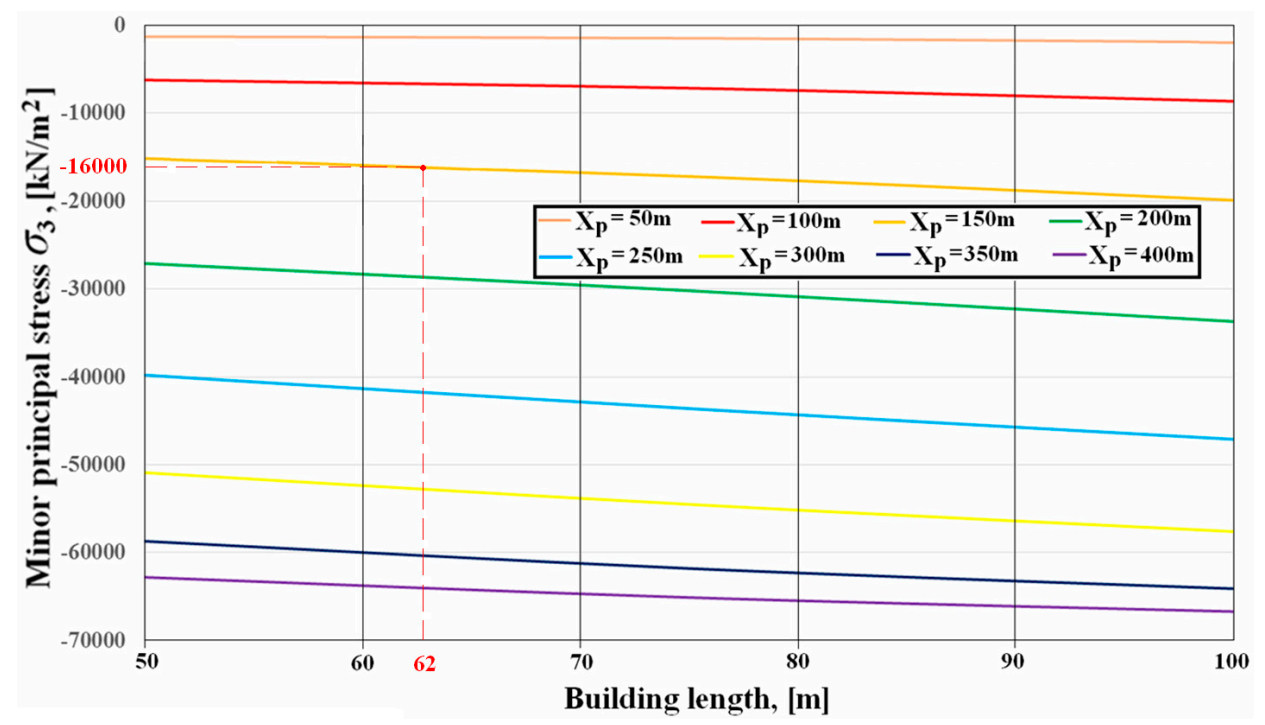

Figure 17. Evolution of the maximum values of minimum principal stresses $\sigma_{3}$ for reinforced concrete buildings, depending on the length of the building.

Depending on the extent of the area under exploitation, minor stresses also maintain the same tendency, which is more pronounced in the range of $X_{p}=175-325 \mathrm{~m}$ and slower for the rest of the panel operating intervals. Comparing these values with the compressive failure strength of the concrete, it can be noted that it is exceeded in the length of the gob by $X_{p}=150 \mathrm{~m}$.

From the scalar representation of stresses in the building structure (Figure 18), it is found that once the mining of the panel begins, the greatest stresses are in the lower part of the building, in the corners closest to the foundation of the area under exploitation. As mining of the coal seam progresses, stresses affect the entire structure of the building, with a decrease in their value towards the center of the building. In the final phase of the operation, the most affected areas of the building are the corners of the foundation and the lower and upper corners of the windows.

Buildings with masonry walls and reinforced concrete floors.

Regarding masonry buildings, a significant decrease of the maximum values of the principal stresses is observed by approximately 10 times in the masonry walls of the building, along with a significant transfer of stress concentration to the reinforced concrete floors. For each mining sequence, a slower increase of stresses in buildings up to $70 \mathrm{~m}$ in length can be observed, followed by a doubling of stresses in the floor between the two levels and a less significant increase in the walls. 
This phenomenon is generated by the fact that the bending rigidity of the brick walls is less important, which causes the stresses developed in the building due to the deformation of the foundation ground to be taken over by the two floors, especially by the floor that separates the two levels of the building.

As for the development of the principal stresses, depending on the extension of the panel operation, for all building lengths, these stresses follow the growth trends presented in the previous subchapter. This means that the main stresses grow more slowly in the ranges of $X_{p}=50-175 \mathrm{~m}$ and $X_{p}=325-400 \mathrm{~m}$, and are more pronounced in the range of $X_{p}=175-325 \mathrm{~m}$.

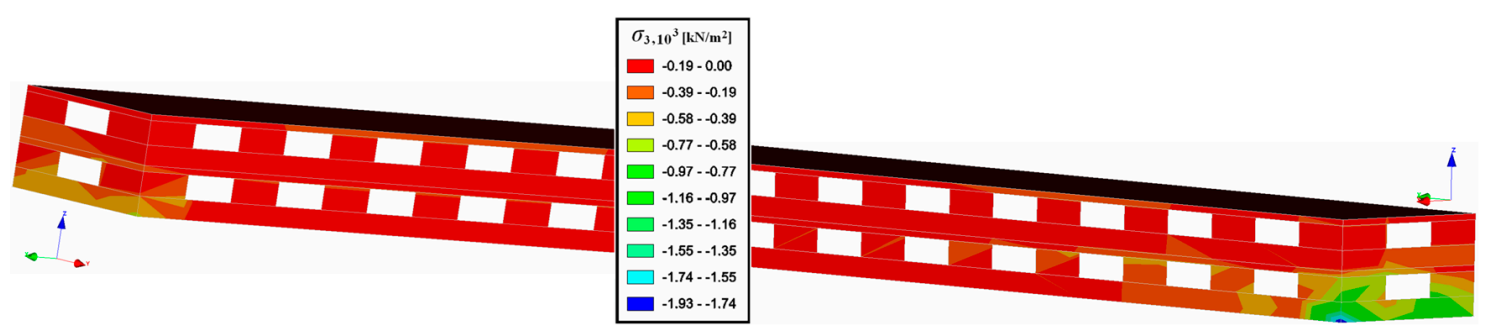

Figure 18. Distribution of minor principal stresses $\sigma_{3}$ at the ends of the building for a reinforced concrete building measuring $100 \mathrm{~m}$ in length and with $X_{p}=50 \mathrm{~m}$.

Analyzing the distribution of stresses in the structures of the masonry buildings, we remark that the principal stresses, in terms of absolute values, are detected in the floor that separates the two levels of the structure, in the areas above the windows and to a lesser degree in the corners of the foundations of the building (as opposed to reinforced concrete buildings).

For brick wall buildings, major principal stresses $\sigma_{1}$ (Figure 19) in their structures are up to three times smaller than those seen in concrete buildings. Additionally, we can remark that there are important differences between the values of major stresses that appeared in buildings of different lengths. In this case, stresses with the highest values appear in the case of masonry buildings measuring $100 \mathrm{~m}$ long.

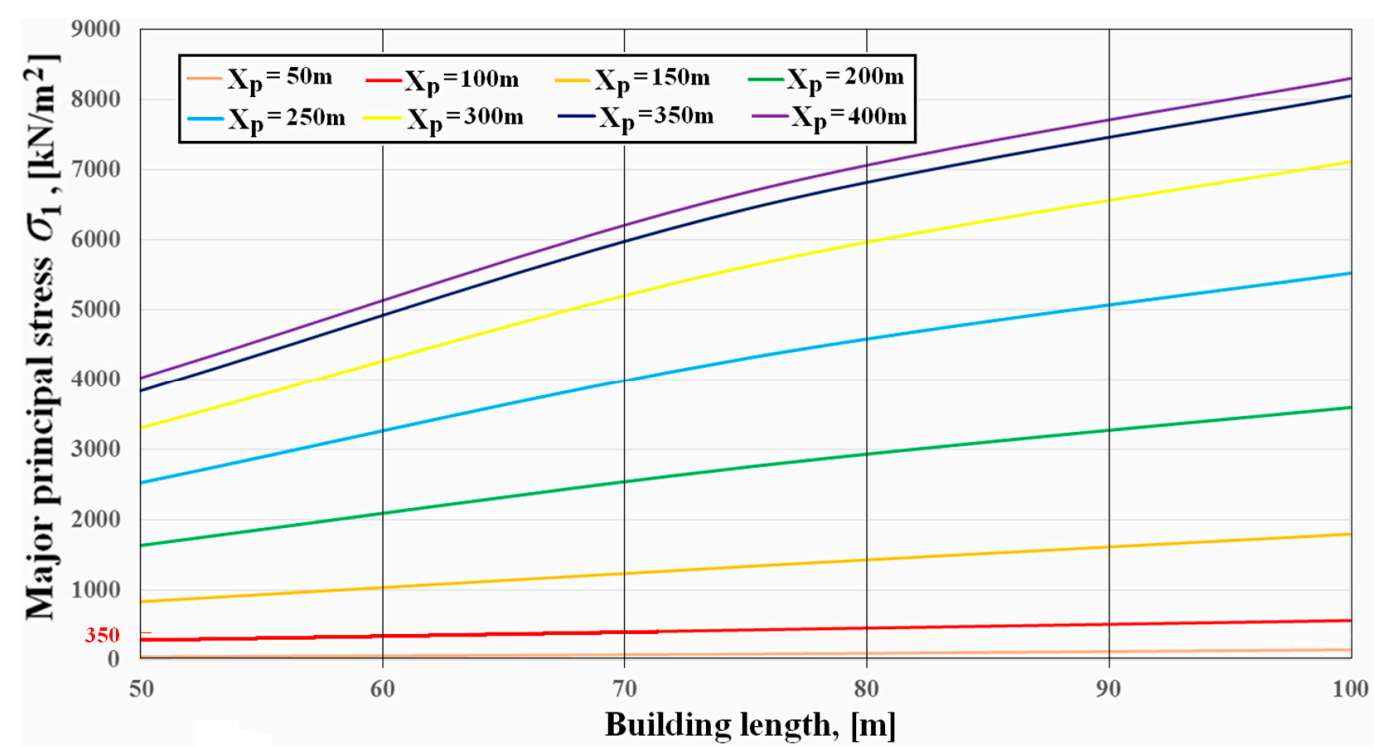

(a)

Figure 19. Cont. 


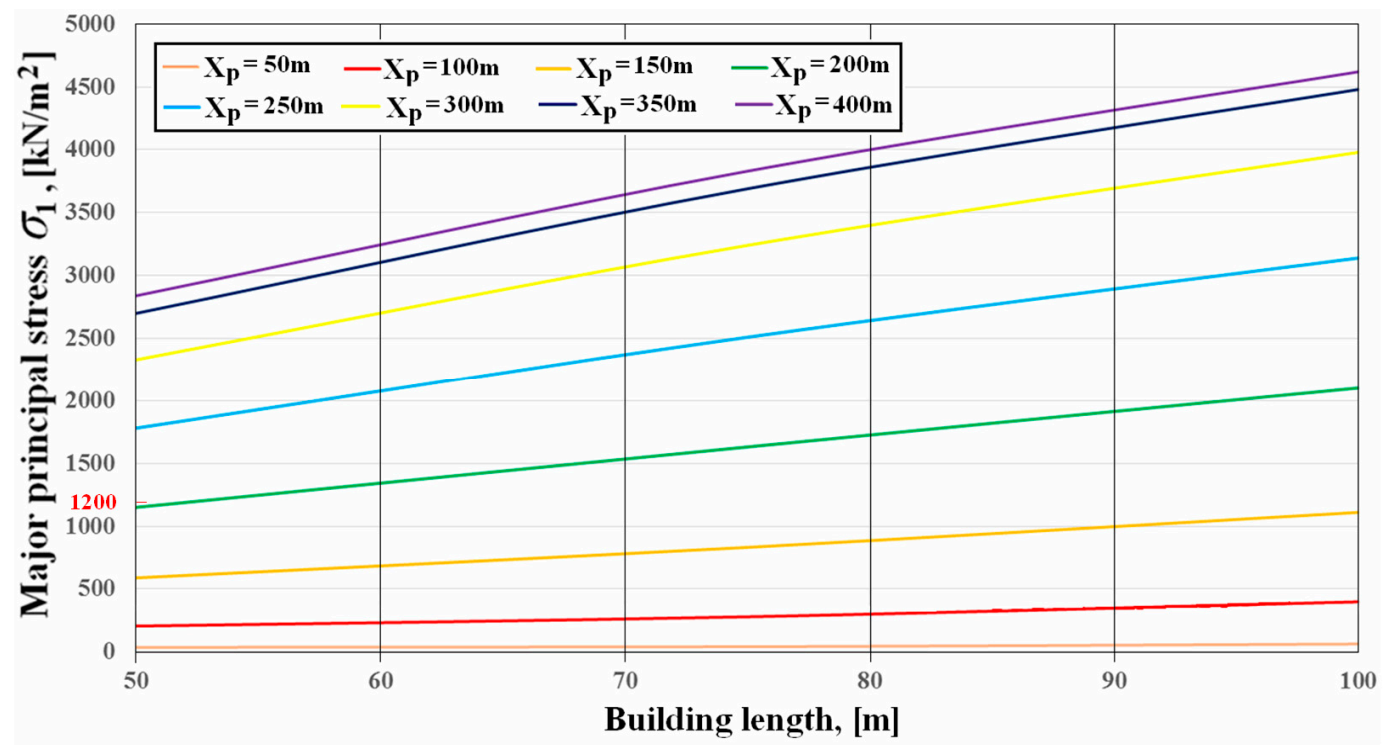

(b)

Figure 19. Evolution of the maximum values of major principal stresses $\sigma_{1}$ for masonry buildings, depending on the length of the building: (a) in the walls; (b) in the floors.

The increase of stresses, both in floors and in masonry walls, is more accentuated for buildings measuring approximately $70-75 \mathrm{~m}$ in length, and slowly decreases above this value.

Additionally, one may notice that for the first mining sequences of the panel, the rate of increase of major and minor stresses depending on the increase of the length of the buildings is insignificant, increasing as the panel operation is extended.

It should be noted that the maximum values of major principal stresses reach the limit of tensile strength of the brick masonry for mined panels with lengths of over $X_{p}=150 \mathrm{~m}$ and for reinforced concrete floors above $X_{p}=200 \mathrm{~m}$.

The distribution of stresses $\sigma_{1}$ in the structures of masonry buildings is different from that in concrete buildings. In the first case, the greatest stresses appear in the reinforced concrete floor between the two levels of the building, in the area above the windows at the ends of the building (Figure 20).
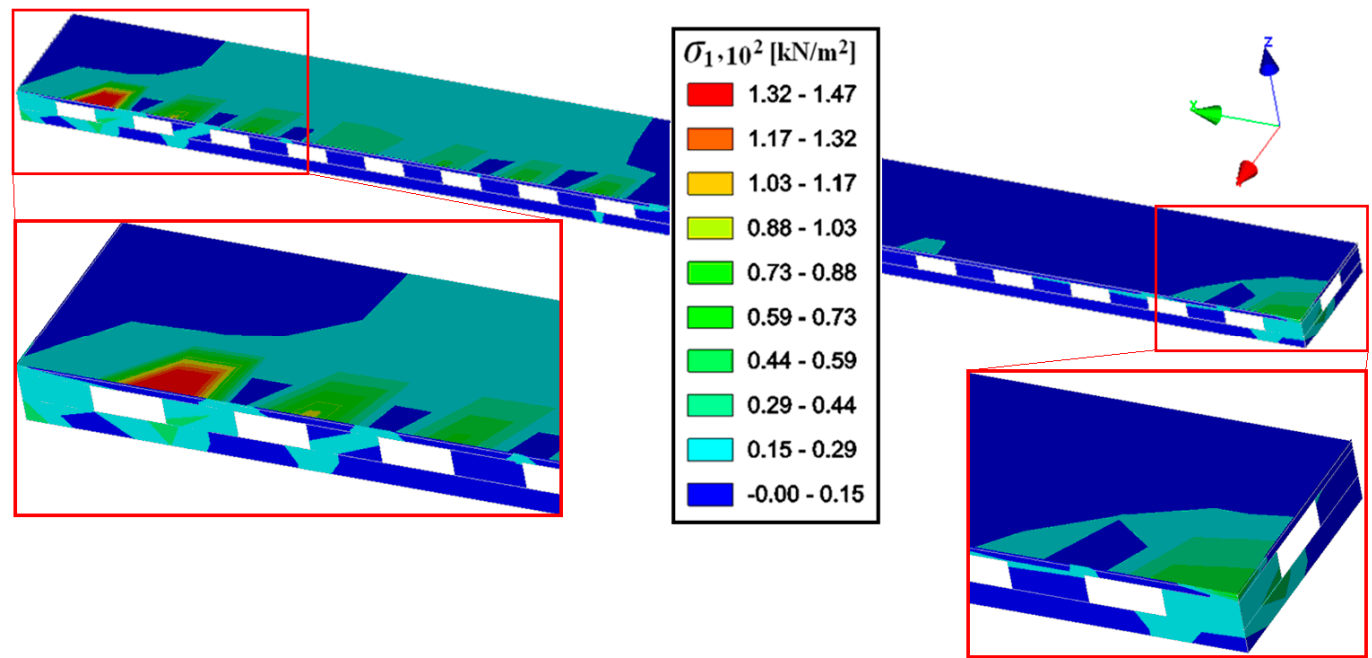

Figure 20. Distribution of major principal stresses $\sigma_{1}$ in the first level of a masonry building with two levels, with a length of $100 \mathrm{~m}$, for a mined panel measuring $X_{p}=50 \mathrm{~m}$ (the upper level is invisible).

As for the minor principal stresses $\sigma_{3}$ developed in the structures of masonry buildings (Figure 21), as a result of underground mining there is immediately a much more marked increase in the walls in 
relation to major principal stresses over the value $X_{p}=70-75 \mathrm{~m}$, and a slower increase in reinforced concrete floors. Additionally, it can be seen that the failure of the compressive phenomenon in the brick walls occurs only when the mined panel exceeds $X_{p}=350 \mathrm{~m}$. As one can see in Figure $21 \mathrm{~b}$, due to the stress redistribution in the structural elements of the buildings, regardless of their modelled length, the compressive failure of the reinforced concrete floors does not occur within the limits of the operation of a panel measuring $400 \mathrm{~m}$ in length.

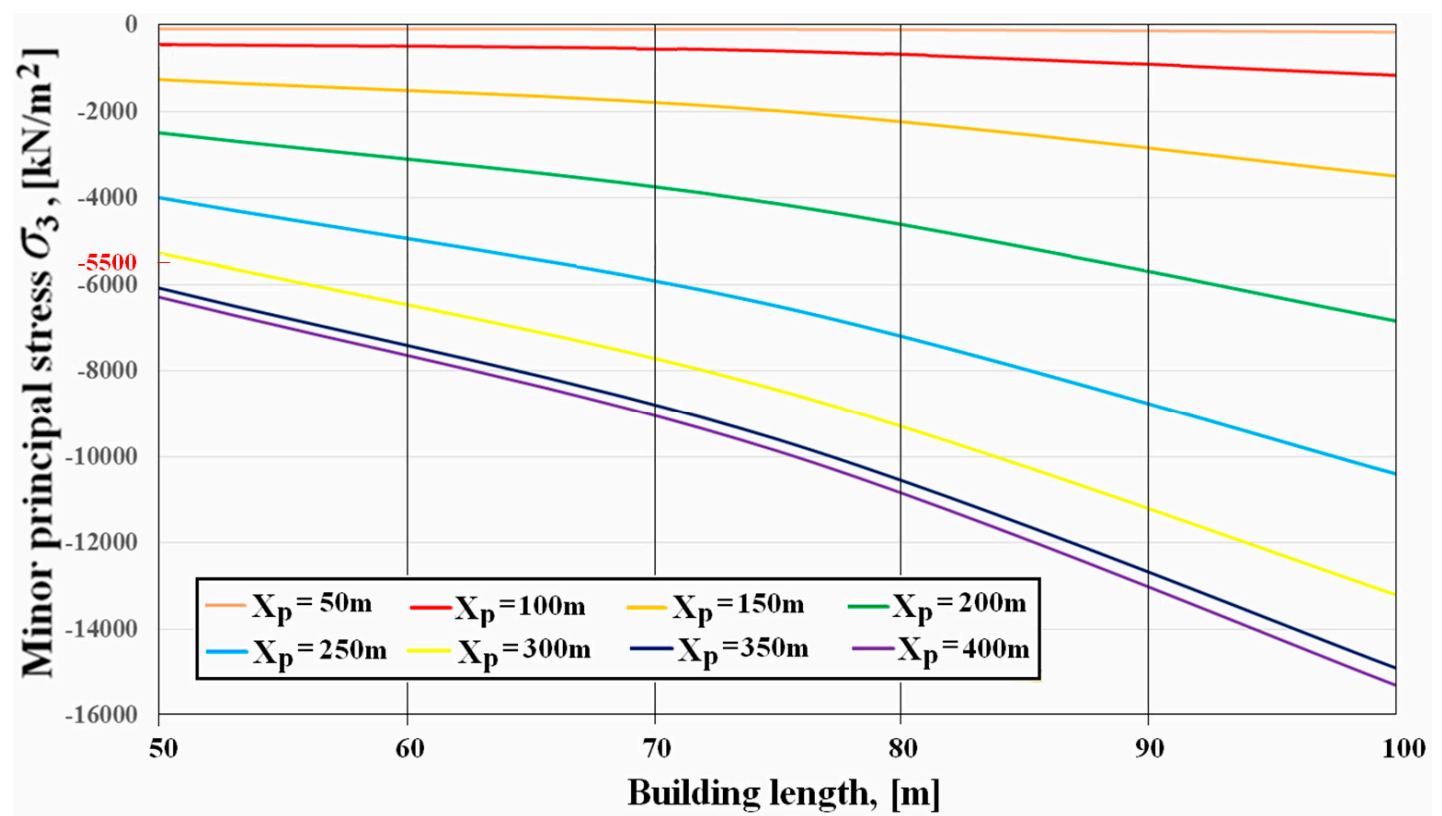

(a)

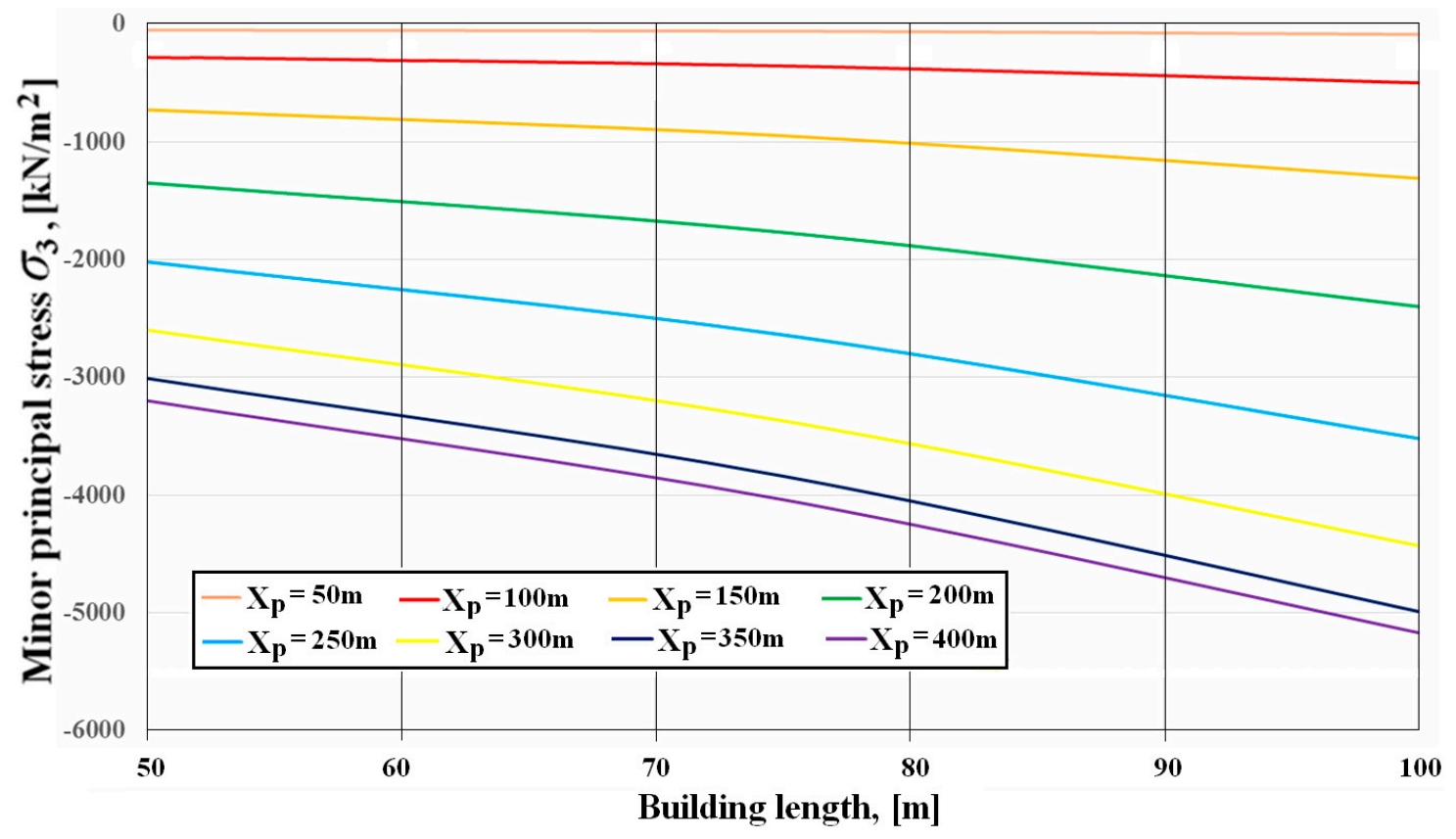

(b)

Figure 21. Evolution of maximum values of minor principal stresses $\sigma_{3}$ for masonry buildings, depending on the length of the building: (a) in the walls; (b) in the floors.

At the beginning of the panel mining, as with the distribution of major stresses, the most important minor stresses, which are marked by a strong asymmetry towards the mined panel, appear on the floor 
between the two levels of the building, especially in the joints between the floor and the walls on the long sides of the building in the areas above the windows (Figure 22). These stresses are redistributed to the walls as the panel mining expands and become symmetrically arranged along the building at the final exploitation of the panel.

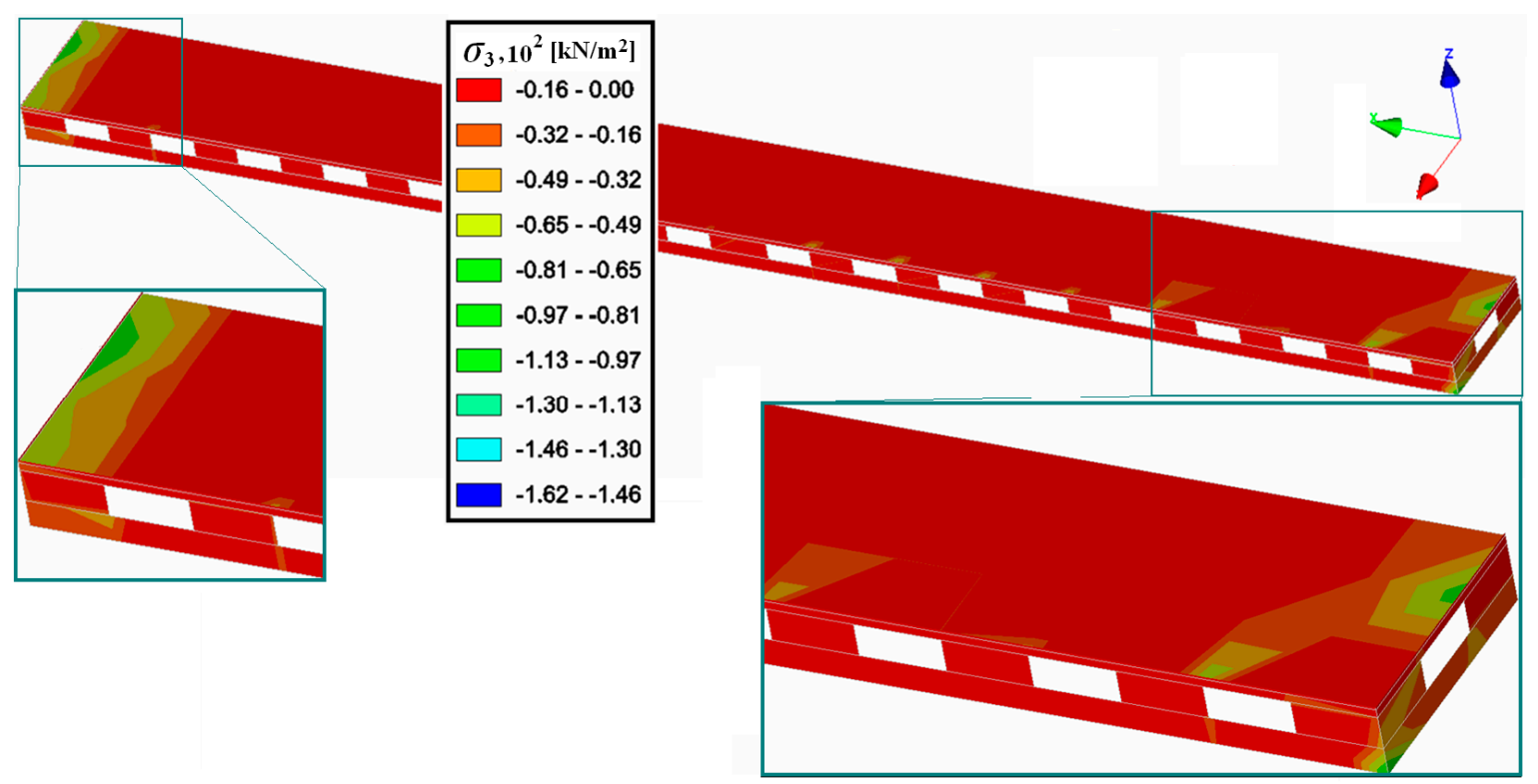

Figure 22. Distribution of the maximum values of minor principal stresses in the first level of a masonry building with a length of $100 \mathrm{~m}$, at a gob length of $X_{p}=50 \mathrm{~m}$ (the upper level is invisible).

\section{Conclusions}

The Jiu Valley mining basin is the most important coal basin in Romania, the exploitation of which began as early as the 19th century. Due to the coal seams having various configurations and complicated tectonics, with varying thicknesses and dips, over time numerous mining methods and technologies have been applied, including short, medium, and long wall faces along the entire thickness of the coal seam or divided into horizontal or inclined slices, all with roof control by integral caving of the surrounding rocks. Since 1996, for the mining of thick coal seams, the longwall mining method with top coal caving has been applied.

The practice of caving the surrounding rocks, due to the large mined height of the coal seams, led to the ground surface being affected. As such, the subsidence of the land appeared, ranging from several tens of meters for the thick coal seams mining to a few meters for other coal seams. Over time, the ground surface deformation has been monitored using topographic, photogrammetric, and aerial laser scanning methods.

Even if the main safety pillars were correctly designed for the main objectives on the surface or underground, there have been cases of accidental crossing of these borders that have led to damage to objects that should have been protected. Also, due to the important coal reserves totalling almost one billion tons that are immobilized in these pillars, their future exploitation is a problem.

The objective of this study is to analyze the behaviour and the state of stresses developed in the structures of the typical buildings in the Jiu Valley following the accidental or planned exploitation of the main safety pillars. In this respect, numerical modelling was used, utilizing the finite element method. The method simulated buildings with one, two, and three levels with a constant horizontal surface, and two-level buildings with constant width and variable length. The buildings were made from reinforced concrete or masonry walls under the influence of sequential underground mining of a panel with a longwall face, containing a coal seam located in geo-mining conditions specific to the Jiu Valley mines. 
Following the analysis of the distribution of stresses in the structures of the modelled buildings, in comparison with the strength characteristics of the building materials, the following important conclusions were reached:

(1) The maximum values of the principal stresses developed in all the modelled buildings, depending on the extension of the mined panel, show greater increases in the range of $X_{p}=175-325 \mathrm{~m}$ and lower increases in the ranges of $X_{p}=50-175 \mathrm{~m}$ and $X_{p}=325-400 \mathrm{~m}$;

(2) Regardless of the number of modelled levels and the extension of the mined panel, the stress concentration is limited to the first level and near the window frames;

(3) As the mining of the panel expands, the state of stresses in the building structure starts as an extremely asymmetric one (for $X_{p}=50 \mathrm{~m}$ ), with the maximum stresses concentrated towards the gob at the beginning of the mining. It continues to balance gradually as the panel is mined by transferring the stresses concentration at the opposite end of the building into a perfectly symmetrical distribution when the panel is completely removed (for $X_{p}=400 \mathrm{~m}$ );

(4) In the case of buildings made entirely of precast, reinforced concrete panels, regardless of the length of the buildings taken into consideration for the finite element analysis or the position of the working coal face, the stresses are concentrated in the walls and are insignificant on the first floor above the first level of the building, due to the high bending rigidity of the walls. Also, the stresses increase almost linearly as the length of the building is also increased, reaching a maximum for the modelled length of $100 \mathrm{~m}$ and for the full exploitation of the panel $\left(X_{p}=400 \mathrm{~m}\right)$;

(5) Under the conditions of brick-walled buildings and reinforced concrete floors, stresses remain in the walls, but due to their reduced bending rigidity, a significant part of the stresses is redistributed on the floor above the bottom level of the building. As such, most major principal stresses in the walls are approximately $40 \%$ greater than on the floor, and minor stresses are approximately three times greater in masonry walls than in reinforced concrete floors. These grow slowly for concrete building with lengths ranging 70-75 m, and are then more accentuated after this length, regardless of the working coal face position.

Author Contributions: D.P.M. realized the numerical models and interpreted the in situ measurements. I.O. conceptualized the numerical models, interpreted the results, and wrote the paper. R.-R.M. collected the data and performed the in situ measurements. D.-A.F. made the numerical models. All authors have read and agreed to the published version of the manuscript.

Funding: This research received no external funding.

Conflicts of Interest: The authors declare no conflict of interest.

\section{References}

1. Onica, I.; Mihailescu, V.; Andrioni, F. Economical optimization of the mechanized longwall faces with top coal caving mining, in horizontal slices. Arch. Min Sci. 2016, 61, 651-676. [CrossRef]

2. Govindan, K.; Kannan, D.; Shankar, K.M. Evaluating the drivers of corporate social responsibility in the mining industry with multi-criteria approach: A multi-stakeholder perspective. J. Clean Prod. 2014, 84, 214-232. [CrossRef]

3. Abdallah, M.; Verdel, T. Behavior of a masonry wall subjected to mining subsidence, as analyzed by experimental designs and response surfaces. Int. J. Rock Mech. Min. Sci. 2017, 100, 199-206. [CrossRef]

4. Andrioni, F. Social-economic influences of mining syncopes in the Jiu Valley over the members of the community. Ann. Petroşani Univ.-Mining Eng. 2017, 18, 178-189.

5. Andrioni, F. Contemporary Social Work between Theory and Practice; Academica Greifswald: Greifswald, Germany, 2018.

6. Onica, I.; Chiril, G. Top Coal Caving Mining in Longwall Faces; AGIR Publishing House: Bucharest, Romania, 2005. (In Romanian)

7. Cao, W.; Wang, X.; Li, P.; Zhang, D.; Sun, C.; Qin, D. Wide strip backfill mining for surface subsidence control and its application in critical mining conditions of a coal mine. Sustainability 2018, 10, 700. [CrossRef] 
8. Wang, X.F.; Qin, D.D.; Zhang, D.S.; Sun, C.D.; Zhang, C.G.; Xu, M.T.; Li, B. Mechanical characteristics of super high-water content material concretion and its application in longwall backfilling. Energies 2017, 10, 1592. [CrossRef]

9. Zhang, J.X.; Zhang, Q.; Sun, Q.; Gao, R.; Germain, D.; Abro, S. Surface subsidence control theory and application to backfill coal mining technology. Environ. Earth Sci. 2015, 74, 1439-1448. [CrossRef]

10. Skrzypkowski, K. Compressibility of materials and backfilling mixtures with addition of solid wastes from flue-gas treatment and fly ashes. E3S Web Confer. 2018, 71, 00007. [CrossRef]

11. Skrzypkowski, K.; Korzeniowski, W.; Poborska-Młynarska, K. Binding capability of ashes and dusts from municipal solid waste incineration with salt brine and geotechnical parameters of the cemented samples. Arch. Min. Sci. 2018, 63, 903-918.

12. Bell, F.G.; Stacey, T.R.; Genske, D.D. Mining subsidence and its effect on the environment: Some differing examples. Environ. Geol. 2000, 40, 135-152. [CrossRef]

13. Bétournay, M.C.; Boyle, R.; Li, G. Impact of regional distressing form intense mining on long-term inactive mine stability, Timmins, Ontario. In Proceedings of the 55th Canadian Geotechnical Conference, Niagara Falls, Ontario, 20-23 October 2002.

14. Tajduś, K. Mining-induced surface horizontal displacement: The case of BW Prosper Haniel Mine. Arch. Min. Sci. 2013, 58, 1037-1055.

15. Brady, B.H.G.; Brown, E.T. Rock Mechanics for Underground Mining, 3rd ed.; Kluwer Academic Publishers, Springer Science + Business Media, Inc.: New York, NY, USA, 2005.

16. Giardina, G.; Milillo, P.; DeJong, M.J.; Perissin, D.; Milillo, G. Evaluation of InSAR monitoring data for post-tunnelling settlement damage assessment. Struct. Control Health Monit. 2018, 26, e2285. [CrossRef]

17. Choi, J.K.; Wom, J.S.; Lee, S.; Kim, S.W.; Kim, K.D.; Jung, H.S. Integration of a subsidence model and SAR interferometry for a coal mine subsidence hazard map in Taebaek, Korea. J. Environ. Plan Manag. 2011, 32, 8161-8181. [CrossRef]

18. Guo, W.; Bai, E.; Yang, D. Surface Subsidence Characteristics and Damage Protection Techniques of High-Intensity Mining in China, Advances in Coal Mine Ground Control; Peng, S., Ed.; Woodhead Publishing Series in Energy; Elsevier Ltd.: Cambridge, UK, 2017; pp. 157-203.

19. Asadi, A.; Shahriar, K.; Goshtasbi, K.; Najm, K. Development of a new mathematical modelling for prediction of surface subsidence due to inclined coal seams mining. J South Afr. Inst. Min. Metall. 2005, 105, 15-20.

20. Onica, I. Impact of the Mineral Deposits Mining on the Environment; Universitas Publishing House: Petroşani, Romania, 2001. (In Romanian)

21. Sanmiquel, L.; Bascompta, M.; Vintró, C.; Yubero, T. Subsidence management system for underground mining. Minerals 2018, 8, 243. [CrossRef]

22. Liu, G. Numerical Modelling of Damage to Masonry Buildings Due to Tunnelling. Ph.D. Thesis, University of Oxford, Oxford, UK, 1997.

23. Pickhaver, J.A. Numerical Modelling of Building Response to Tunnelling. Ph.D. Thesis, University of Oxford, Oxford, UK, 2006.

24. Kappen, J.M.J.; Giardina, G.; Hendriks, M.A.N.; Rots, J.G. 3D Numerical analysis of tunnelling induced damage: The influence of the alignment of a masonry building with the tunnel axis. In Proceedings of the EURO: TUN 2013: 3rd International Conference on Computational Methods in Tunneling and Subsurface Engineering, Bochum, Germany, 17-19 April 2013.

25. Molins, C.; Camós, C. Study of the sensitivity of different building structures to tunneling induced settlements. In Proceedings of the Second International Conference on Structures and Architecture, Guimaraes, Portugal, 24-26 July 2013; CRC Press: Boca Raton, FL, USA, 2013; pp. 704-711.

26. Bharti, R.K.; Gupta, M.; Kumar, N. Stresses below existing structures during tunnel excavation using tunnel boring machine (TBM). IJIERT 2015, 2, 1-7.

27. Zaw, A.; Dhiraj, K.; Christian, S. Ground movement prediction and building damage risk-assessment for the deep excavations and tunneling works in Bangkok subsoil. In Proceedings of the International Symposium on Underground Excavation and Tunneling, Bangkok, Thailand, 2-4 February 2006; pp. 281-297.

28. Vahdatirad, M.J.; Ghodrat, H.; Firouzian, S.; Barari, A. Analysis of an underground structure settlement risk due to tunnelling-A case study from Tabriz, Iran, Songklanakarin. J. Sci. Technol. 2010, 32, 145-152.

29. Son, M.; Cording, E.J. Numerical model tests of building response to excavation-induced ground movements. Can. Geotech. J. 2008, 45, 1611-1621. [CrossRef] 
30. Camós, C.; Molins, C.; Arnau, O. A case study of damage on masonry buildings produced by tunneling induced settlements. Int. J. Archit. Herit. 2014, 8, 602-625. [CrossRef]

31. Amorosi, A.; Boldini, D.; De Felice, G.; Malena, M.; Sebastianelli, M. Tunnelling-induced deformation and damage on historical masonry structures. Géotechnique 2014, 64, 118-130. [CrossRef]

32. Giardina, G.; Hendriks, M.A.N.; Rots, J.G. Numerical analysis of tunnelling effects on masonry buildings: The influence of tunnel location on damage assessment. In Advanced Materials Research; Gu, X., Song, X., Eds.; Shanghai, Trans Tech Publications: Zurich, Switzerland, 2010; Volume 133-134, pp. 289-294.

33. Deck, O.; Al Heib, M.; Homand, F. Study of the consequences of mining subsidences on constructions through numerical modelling (in French). In Proceedings of the 14th French Congress of Mechanics, Nancy, France, 3-7 September 2001; pp. 460-467.

34. Deck, O.; Anirudh, H. Numerical study of the soil-structure interaction within mining subsidence areas. Comput. Geotech. 2010, 37, 802-816.

35. Caudron, M.; Emeriault, F.; Kastner, R.; Al Heib, M. Collapses of underground cavities and soil-structure interactions: Experimental and numerical models. In Proceedings of the 1st Euro Mediterranean symposium on advances on geomaterials and structures, Hammamet, Tunisia, 3-5 May 2006; pp. 311-316.

36. Peng, S.S. Coal Mine Ground Control; China University of Mining and Technology Press: Xuzhou, China, 2008.

37. Deck, O. Study of the Consequences of Mining Subsidence on Buildings (in French). Ph.D. Thesis, Polytechnical National Institute of Lorraine, Nancy, France, 2002.

38. Saeidi, A. Vulnerability of Workings Subject to the Dangers of Ground Movements; Development of a Damage Simulator (in French). Ph.D. Thesis, Polytechnical National Institute of Lorraine, Nancy, France, 2010.

39. Kratzsch, H. Mining Subsidence Engineering; Springer: Berlin, Germany, 1983.

40. Bruhn, W.R.; Speck, R.C.; Thill, R.E. The Appalachian Field: Damage to Structure above Active Underground Mine. In Surface Mining Environmental Reclamation Handbook; Elsevier: New York, NY, USA, 1983.

41. Sengupta, M. Environmental Impacts of Mining, Monitoring, Restoration and Control; Lewis Publishers: Boca Raton, NY, USA, 1993.

42. Wardell, K. Surface Ground Movements Associated with the Total and Partial Extraction of Stratified Mineral Deposits. Master's Thesis, University of Nottingham, Nottingham, UK, 1965.

43. Mine Subsidence Engineering Consultants of Chatswood (Australia). Mine Subsidence Damage to Building Structures. 2007. Available online: http://www.minesubsidence.com/index_files/files/Mine_Subs_Damage_ to_Bldg_Structures.pdf (accessed on 4 August 2019).

44. Toraño, J.; Rodriguez, R.; Ramirez-Oyanguren, P. Probabilistic analysis of subsidence-induced strains at the surface above steep seam mining. Int. J. Rock Mech. Min. Sci. 2000, 37, 1161-1167. [CrossRef]

45. Onica, I.; Marian, D. Ground surface subsidence as effect of underground mining of the thick coal seams in the Jiu Valley Bassin. Arch. Min. Sci. 2012, 57, 547-577.

46. Guéguen, Y.; Deffontaines, B.; Al Heib, M.; Fruneau, B.; De Michele, M.; Raucoules, D.; Guise, Y.; Planchenault, J. Detection and characterisation of residual mining subsidence using DINSAR and PS Interferometry: Application to Nord Pas-De-Calais Coalbasin (Northern France). In Proceedings of the Envisat Symposium, Montreux, Switzerland, 23-27 April 2007.

47. Xiong, L.; Wang, G.; Bao, Y.; Zhou, X.; Sun, X.; Zhao, R. Detectability of repeated airborne laser scanning for mountain landslide monitoring. Geosciences 2018, 469, 1-18.

48. Liu, X. Airborne LiDAR for DEM generation: Some critical issues. Prog. Phys. Geogr. Earth Environ. 2008, 32, 31-49.

49. Marian, D.P.; Onica, I.; Cozma, E. Sensibility analysis of the subsidence parameters at the variation of the main geo-mining factors. Mining Revue 2011, 17, 29-35.

50. Cai, M.; He, M.; Liu, D. Rock Mechanics and Engineering; Science Press: Beijing, China, 2013; pp. 32-38.

51. Gao, Y.; Liu, D.; Zhang, X.; He, M. Analysis and optimization of entry stability in underground longwall mining. Sustainability 2017, 9, 2079. [CrossRef]

52. Herget, G. Stresses in Rock; AA Balkema Publisher: Rotterdam, The Netherland, 1987.

(C) 2020 by the authors. Licensee MDPI, Basel, Switzerland. This article is an open access article distributed under the terms and conditions of the Creative Commons Attribution (CC BY) license (http://creativecommons.org/licenses/by/4.0/). 